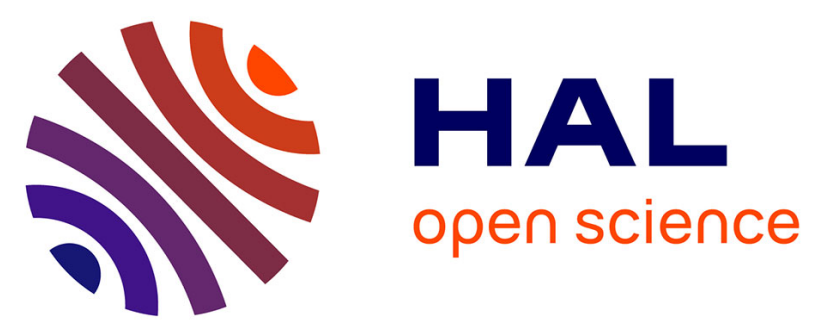

\title{
Induction of osteogenesis in mesenchymal stem cells by activated monocytes/macrophages depends on oncostatin $M$ signaling.
}

Pierre Guihard, Yannic Danger, Bénédicte Brounais, Emmanuelle David, Régis Brion, Joël Delecrin, Carl D. Richards, Sylvie Chevalier, Françoise Rédini, Dominique Heymann, et al.

\section{To cite this version:}

Pierre Guihard, Yannic Danger, Bénédicte Brounais, Emmanuelle David, Régis Brion, et al.. Induction of osteogenesis in mesenchymal stem cells by activated monocytes/macrophages depends on oncostatin M signaling.. Stem Cells / Stem Cells (Miamisburg), 2012, 30 (4), pp.762-72. 10.1002/stem.1040 . inserm-00668995

\section{HAL Id: inserm-00668995 https://www.hal.inserm.fr/inserm-00668995}

Submitted on 20 Jul 2012

HAL is a multi-disciplinary open access archive for the deposit and dissemination of scientific research documents, whether they are published or not. The documents may come from teaching and research institutions in France or abroad, or from public or private research centers.
L'archive ouverte pluridisciplinaire HAL, est destinée au dépôt et à la diffusion de documents scientifiques de niveau recherche, publiés ou non, émanant des établissements d'enseignement et de recherche français ou étrangers, des laboratoires publics ou privés. 


\section{Induction of bone formation by activated monocytes / macrophages depends on Oncostatin $M$ signaling}

Pierre Guihard ${ }^{\mathrm{a}, \mathrm{b}}$, Yannic Danger ${ }^{\mathrm{c}}$, Bénédicte Brounais ${ }^{\mathrm{a}, \mathrm{b}, 2}$, Emmanuelle David ${ }^{\mathrm{a}, \mathrm{b}}$, Régis Brion $^{\mathrm{a}, \mathrm{b}}$, Joël Delecrin ${ }^{\mathrm{d}}$, Carl D. Richards ${ }^{\mathrm{e}}$, Sylvie Chevalier ${ }^{\mathrm{c}}$, Françoise Rédini, ${ }^{\mathrm{a}, \mathrm{b}}$, Dominique Heymann $^{\mathrm{a}, \mathrm{b}}$, Hugues Gascan ${ }^{\mathrm{c}}$, Frédéric Blanchard ${ }^{\mathrm{a}, \mathrm{b}}$

${ }^{\mathrm{a}}$ INSERM, U957, ${ }^{\mathrm{b}}$ Université de Nantes, Laboratoire de Physiopathologie de la Résorption Osseuse et Thérapie des Tumeurs Osseuses Primitives, EA3822, Nantes, France ; ${ }^{\mathrm{I}}$ INSERM, U564, F-49033 Angers, France; ${ }^{\mathrm{d}} \mathrm{CHU}$ de Nantes, service d'Othopédie-Traumatologie, F44035 Nantes, France; and ${ }^{\mathrm{e}}$ McMaster University, Center for Gene Therapeutics, Hamilton, Ontario L8S4L8, Canada

Author contributions: H.G., F.R., D.H. and F.B. designed research; P.G, B.B., E.D., R.B. and Y.D. performed research; P.G., Y.D. and F.B. analyzed data; J.D. and C.D.R. contributed new reagents or analytic tools; P.G. and F.B. wrote the paper.

Classification: BIOLOGICAL SCIENCES, Cell biology.

${ }^{1}$ To whom correspondence should be addressed: Frédéric Blanchard, INSERM U957, Faculté de Médecine, 1 rue Gaston Veil, F-44035 Nantes, France. Tel: 33-2-40-41-29-60. Fax: 33-240-41-28-60. E-mail: frederic.blanchard@univ-nantes.fr

${ }^{2}$ Present address: Division of Bone Diseases, Department of Rehabilitation and Geriatrics, Geneva University Hospital, 1211 Geneva 14, Switzerland 


\section{Abstract}

Bone resorption by osteoclasts and bone formation by osteoblasts are tightly coupled processes implicating factors in $\mathrm{TNF}$, bone morphogenetic protein and Wnt families. In osteoimmunology, macrophages were described as another critical cell population regulating bone formation by osteoblasts but the coupling factors were not identified. Using a high throughput approach, we identified here Oncostatin M (OSM), a cytokine of the IL-6 family, as a major coupling factor produced by activated circulating $\mathrm{CD} 14^{+}$or bone marrow $\mathrm{CD} 11 \mathrm{~b}^{+}$ monocytes/macrophages that induces osteoblast differentiation and matrix mineralization from human mesenchymal stem cells (MSC) while inhibiting adipogenesis. Upon toll-like receptors (TLRs) activation by lipopolysaccharide or endogenous ligands, OSM was produced in classically activated inflammatory M1 and not M2 macrophages, through a cyclooxygenase-2 and prostaglandin-E2 regulatory loop. Stimulation of osteogenesis by activated monocytes/macrophages was prevented using neutralizing antibodies or siRNA to OSM, OSM receptor subunits gp130 and OSMR or to the downstream transcription factor STAT3. The induced osteoblast differentiation program culminated with enhanced expression of $\mathrm{C} / \mathrm{EBP} \delta$ (CCAAT-enhancer-binding protein $\delta$ ), $\mathrm{Cbfa} 1$ and alkaline phosphatase. Overexpression of OSM in the tibia of mice has led to new bone apposition with no sign of bone resorption. Two other cytokines had also a potent role in bone formation induced by monocytes/macrophages and TLRs activation: IL-6 and Leukemia inhibitory factor. We propose that during bone inflammation, infection or injury, the IL-6 family signaling network activated by macrophages and TLR ligands stimulates bone formation that is largely uncoupled from bone resorption and is thus an important target for anabolic bone therapies. 
Bone is a dynamic mineralized tissue which is continuously resorbed by osteoclasts and rebuilt by osteoblasts. Osteoclast precursors are hematopoietic cells of the monocyte/macrophage lineage whereas osteoblast precursors are multipotent mesenchymal stem cells (MSC) that can also give rise to adipocytes and chondrocytes. Under physiological conditions, bone resorption is precisely replaced by new bone formation and therefore osteoclast and osteoblast activities are tightly coupled. Indeed, osteoblasts control osteoclast differentiation mainly through RANKL (receptor activator of nuclear factor kappa-B ligand) and inversely osteoclast control osteoblast differentiation through Wnt10b and BMP6 (bone morphogenetic protein 6) for example $(1,2)$. Immune cells such as $\mathrm{T}$ lymphocytes also control bone homeostasis or pathology in a field of research called osteoimmunology. More recently, bone resident macrophages, termed osteomacs, have been described as another critical immune cell population regulating bone formation by osteoblasts (3). However the coupling factors produced by osteomacs were not identified.

Despite their role as osteoclast precursors, monocytes/macrophages play major roles in innate immunity and in the regulation of the adaptive immune response. Once activated by microbial products such as the prototypical Toll-like receptor (TLR) agonist LPS, they acquire microbicidal competence and can produce huge amount of pro-inflammatory mediators such as IL-1 $\beta$, TNF $\alpha$, IL-6 or prostaglandin E2 (PGE2)(4). In culture, classically activated macrophages termed M1 macrophages can be obtained from peripheral monocytes when stimulated with IFN $\gamma$ whereas alternative activation of macrophages (M2) induced by IL-4 or IL-10 leads to tissue repair and suppression of inflammation (4). Increased numbers of activated macrophages are a prominent feature of inflammatory lesions and in the case of rheumatoid arthritis (RA), the presence of macrophages in the synovial tissue correlates with 
joint erosions (5). The key role of macrophages in RA is also supported by the successful treatment with $\mathrm{TNF} \alpha$ blockers, considering that $\mathrm{TNF} \alpha$ is mainly produced by activated macrophages (5). Implication of pro-inflammatory mediators in periarticular bone erosions and systemic osteoporosis can be direct through induction of osteoclast differentiation and/or indirect through enhanced RANKL production, the key osteoclastogenic cytokine $(1,6)$.

Although inflammation is invariably related to increased bone resorption, new bone formation can be also observed. In RA, penetration of cortical bone and bone marrow by inflammatory cells is associated with increased bone or osteoid formation, suggesting an attempt to repair bone from the medullar cavity (7). In spondyloarthropathies, inflammation induces excess periosteal bone formation independently of osteoclastic resorption (8). During fracture repair, inflammatory cytokines such as TNF $\alpha$ and IL-6 induce recruitment and osteogenic differentiation of muscle-derived MSC (9). Interestingly bone macrophages are required for fracture repair and bone healing (10). At last in atherosclerosis, activated macrophages produce $\mathrm{TNF} \alpha$ and Oncostatin $\mathrm{M}$ to promote vascular calcification from vascular smooth muscle cells (11). Macrophages thus appear to have an essential role in the regulation of bone formation during inflammation and bone injury and identification of the factors controlling osteogenesis represent an important step to develop new bone anabolic strategies.

Cytokines of the IL-6 family, such as Oncostatin M (OSM) or Leukemia Inhibitory Factor (LIF) share the gp130 subunit (12-14). IL-6 first binds to a specific receptor subunit (IL-6R, either membranous or soluble) that lacks intrinsic signaling properties and then interacts with gp130 to transduce a signal. Mouse OSM first binds to gp130 and then recruits the OSMR. In humans, OSM is exceptional because it interacts with gp130 and with either LIFR or OSMR to form a signaling-competent receptor complex. IL-6-type cytokines are overexpressed systemically and/or locally in several inflammatory diseases associated with 
bone loss, such as RA, inflammatory bowel disease or psoriasis $(12,13,15-18)$. They can be produced by activated $\mathrm{T}$ lymphocytes, macrophages and neutrophils. In co-cultures containing both osteoblasts/stromal cells and osteoclasts precursors, they stimulate osteoclast differentiation and activity (19). In fact, they induce osteoblastic production of various downstream effectors that activate osteoclast differentiation or activity, such as RANKL, IL1, PTHrP and PGE2 $(6,12)$. In vivo, $\mathrm{IL}_{-} 6^{-/}$mice are significantly protected from joint inflammation and destruction in mouse models of arthritis, leading to the tocilizumab IL-6R antibody actually used in chronic inflammatory diseases $(12,13,20)$. However, numerous reports also indicated that these cytokines, especially IL-6+sIL-6R and OSM enhance differentiation of osteoblasts through the transcription factor STAT3, leading to increased bone formation $(12,21-23)$. Therefore these cytokines control both bone resorption and formation.

Using a high throughput approach, we identified here OSM as a major cytokine produced by classically activated monocytes/macrophages that induces osteoblast differentiation and matrix mineralization from MSC. Together with IL-6 and LIF, these 3 cytokines appeared to form a regulatory network controlling bone apposition.

\section{Results}

Activated monocytes/macrophages secrete OSM to induce matrix mineralization by MSC. We first compared, using co-cultures of human circulating CD14 $4^{+}$monocytes and human bone marrow MSC, the effect of RANKL (to obtain osteclast) and LPS (to obtain activated monocytes/macrophages) on the mineralization by MSC. Both treatments similarly induce matrix mineralization (Fig. 1A). To discriminate between soluble and membranous 
mediators, MSC were treated with conditioned media (CM) from LPS-activated CD14 ${ }^{+}$ monocytes. We observed significant induction of mineralization using the $\mathrm{CM}$ from 8 different $\mathrm{CD}_{1} 4^{+}$donors whereas the control CM obtained without LPS treatment (CT) reduced mineralization (4 donors are presented in Fig. 1B). Identical results were obtained with human bone marrow $\mathrm{CD}_{1} 1 \mathrm{~b}^{+}$monocytes treated with LPS (Fig. S2A). Similarly, MSC from 6 different donors responded to a CD14 ${ }^{+} \mathrm{CM}$ (4 donors are presented in Fig. S1A). To be active, the $\mathrm{CD} 14^{+} \mathrm{CM}$ must be added during almost all the culture time, with a minimum of 9 on 12 days (Fig. S1B). Interestingly, the LPS-activated $\mathrm{CD} 14^{+} \mathrm{CM}$ inhibited differentiation of MSC into adipocytes as revealed by the reduced number of cells with lipid droplets (Fig. 1C and 2E), suggesting an inverse effect of activated monocytes/macrophages on osteogenesis and adipogenesis.

To identify the soluble mediators produced by LPS-activated monocytes and implicated in osteoblast maturation, we first used a high throughput quantitative RT-PCR approach that allows the analysis of the genes encoding all known cytokines, chemokines and growth factors (24). On the 161 tested genes, 55 were upregulated by LPS and 1 (CCL24/eotaxin-2) was downregulated (Fig. 2A and Table S1). Mediators with known activities on osteoblasts differentiation were IL-1 $\beta$, IL-6, IL-10, TNF $\alpha$, VEGFA, GCSF and FGF2 for example. LPS also enhanced mRNA level of Wnt and BMP family members (Wnt5a and BMP6) as observed previously in monocytes treated with RANKL (2). Using ELISA and multiplexed dosages (Luminex technology), we could confirm a significant induction of 22 soluble mediators by LPS, two other secreted proteins being reduced (eotaxin2 and sIL-6R)(Table S1). We then used a panel of neutralizing antibodies or other inhibitors to prevent matrix mineralization induced by the CM of LPS-activated circulating $\mathrm{CD} 14^{+}$or 
bone marrow $\mathrm{CD} 11 \mathrm{~b}^{+}$monocytes and identified the IL-6 family, sharing the gp130 receptor subunit (Fig. S1C, Fig. S2A and Table S1).

Among the 9 cytokines in the IL-6 family, only OSM, Leukemia inhibitory factor (LIF) and IL-6 when associated with its soluble receptor (sIL-6R) induced mineralization by MSC (Fig. 2B). However, dose-response experiments indicated that OSM and LIF were active at lower concentrations, with a significant increased mineralization observed with $0.1-1$ ng/ml (Fig. 2C). In comparison, LPS-activated $\mathrm{CD} 14^{+} \mathrm{CM}$ contained sufficient amount of OSM or IL-6 to induce mineralization, but the level of LIF or sIL-6R was too low (Table S1). When using neutralizing antibodies to IL-6, IL-6R, OSM or LIF we identified OSM as a major cytokine implicated in mineralization induced by all LPS-activated CD14 ${ }^{+} \mathrm{CM}$ (Fig. S2B and Fig. 2D). This result was confirmed with the BK5 anti-gp130 antibody that preferentially inhibits OSM signaling (Fig. S2B)(25). However, only the combined neutralization of OSM and LIF totally prevented mineralization to the level obtained with anti-gp130 antibodies, indicating that both cytokines are implicated (Fig. 2D, see below for further description of the role of LIF). Inhibition of adipogenesis by LPS-activated CD14 CM was also prevented using anti-OSM antibodies (Fig. 2E).

The COX2-PGE2 pathway is implicated in OSM production in M1 macrophages. One of the most induced genes in $\mathrm{CD} 14^{+}$monocytes treated with LPS was cyclooxygenase 2 (COX2), and consequently PGE2 were detected in large amount in the LPS-activated CD14 ${ }^{+} \mathrm{CM}$ (Table S1). Because OSM production can be induced by PGE2 (26), we next collected the $\mathrm{CM}$ of LPS-activated $\mathrm{CD} 14^{+}$monocytes treated with the COX inhibitor Meloxicam which is 300 fold more active on COX2 than on COX1 (ref $\neq$ M3935 from Sigma). Inhibition of COX2 leaded to reduced production of PGE2 and OSM whereas IL-6 secretion was reduced only by 
$20 \%$ and sIL-6R production was not significantly affected (Fig. 3B). COX2 inhibition in monocytes also significantly prevented the mineralization induced by the $\mathrm{CD} 14^{+} \mathrm{CM}$ on $\mathrm{MSC}$ (Fig. 3A). In control experiments, we confirmed that (i) PGE2 does not directly induce mineralization on MSC, (ii) COX2 or prostaglandin EP receptor inhibition in MSC does not prevent mineralization induced by the $\mathrm{CD} 14^{+} \mathrm{CM}$ (Fig. S3A) and (iii) concentrations of Meloxicam as low as $5 \mu \mathrm{M}$ were active to reduce OSM secretion by CD14+ monocytes ($54 \%)$ and the induced mineralization by MSC (-82\%). Together these results indicated that LPS induced COX2 and PGE2 production in CD14 ${ }^{+}$monocytes, leading to enhanced OSM secretion and thus to enhanced OSM-driven mineralization by MSC.

The cytokine / chemokine profile of LPS-activated CD14 $4^{+}$monocytes is typical of classically activated M1 macrophages, with high expression of TNF $\alpha$, IL-1 $\beta$, IL-6, IL-8, CCL2, CCL3 and CXCL10 for example (Table S1). To analyze the expression of OSM in other macrophage lineages, M2 macrophages were generated with IL-4 (M2a) or IL-10 (M2c) (4). In comparison to prototypical M1 macrophages generated with IFN $\gamma$, M2 macrophages produced 5 to 10 fold less OSM at basal level or after LPS stimulation (Fig. 3C). Similarly, induction of mineralization by M1 macrophages CM was prevented by OSM or gp130 neutralizing antibodies, whereas M2a or M2c macrophages CM did not induce mineralization by MSC (Fig. 3E and F).

We next analyzed whether OSM was induced by other TLR ligands. Activation of TLR3 using Poly I:C (a synthetic analog of viral double-stranded RNA) or TLR2 and 6 using Zymosan from yeast cell wall also augmented OSM secretion by $\mathrm{CD}_{1} 4^{+}$cells. Similarly, endogenous TLR4 ligands released from the breakdown of extracellular matrices such as hyaluronic acid (HA) and heparan sulfate (HS) were potent inducers of OSM production (Fig. 
3D). Induction of mineralization by these monocytes / macrophages CM correlated with OSM production and was reduced by OSM or gp130 neutralizing antibodies (Fig. 3G and H).

Role of LIF and IL-6. As indicated before, LIF and OSM neutralizing antibodies appeared to synergize to prevent mineralization induced by LPS-activated $\mathrm{CD}_{14}^{+} \mathrm{CM}$ (Fig. 2D) but activated monocytes expressed only low amount of LIF mRNA and the secreted LIF protein could never be detected (Table S1). Moreover the CM from several donors (2 on 8 tested) was sensitive to LIF neutralization alone (see donor $\neq 2$ in Fig. 2D). These donors CM appeared to contain only low amount of OSM (419 pg/ml for donor $\neq 2$ versus 858 and $1184 \mathrm{pg} / \mathrm{ml}$ for donor $\neq 3$ and 4 respectively), suggesting that LIF had a compensatory role when OSM is not sufficiently expressed. To study the production of LIF directly from MSC, we treated these cells with LPS but without monocytes / macrophages. LPS directly induced LIF mRNA and protein secretion in MSC (Fig. S4A and B) and the LIF neutralizing antibody prevented the 2 to 4 fold increased mineralization observed with LPS in the absence of monocytes (Fig. S3A, B and Fig. S4C).

IL-6 mRNA and protein expression was also directly induced by LPS in MSC (Fig. S4A and B) whereas OSM was not produced (below the detection limits in both RT-qPCR and ELISA). Thus OSM was exclusively produced by monocytes/macrophages, LIF only by MSC and IL- 6 by both cell types. However, the neutralizing IL-6 antibody, validated in a plasmacytoma IL-6-dependent bioassay with a ND50 of $0.05-0.15 \mu \mathrm{g} / \mathrm{ml}$ (ref $\neq$ AB-206-NA from R\&D systems) and used here at a 100 fold molar excess over IL-6, never prevented the mineralization induced by activated monocytes (Fig. S2B), presumably because expression of its soluble receptor sIL-6R is too low (Table S1 and Fig. 3C). To confirm this possibility, we added the sIL-6R to MSC cultures treated with LPS-activated $\mathrm{CD} 14^{+} \mathrm{CM}$ and neutralizing 
antibodies to OSM and LIF (Fig. S5). In these conditions, the sIL-6R induced mineralization by MSC.

\section{Activation of the OSMR-STAT3-C/EBPS-Cbfa1 differentiation pathway by OSM in}

MSC. We next analyzed the osteoblast differentiation program initiated by activated monocytes in MSC. The mRNA levels of C/EBP $\delta$ (CCAAT-enhancer-binding protein $\delta$ ) and Cbfa1, two key transcription factors implicated in osteoblast differentiation, were first induced by the LPS-activated $\mathrm{CD} 14^{+} \mathrm{CM}$ within 1-3 days of culture. Thereafter, the 2 osteoblast markers alkaline phosphatase (ALP) and bone sialoprotein (BSP) were induced, just before mineralization can be detected (Fig. 4A and B). Interestingly, mRNA levels of gp130 and OSMR were also induced, suggesting again an activation of this receptor complex. Using the gp130 neutralizing antibody, we confirmed that all these osteoblastic genes were effectively induced in a gp130-dependent manner (Fig. 4A). OSM also induced the mRNA level of C/EBP $\delta$, Cbfa1, ALP, BSP and OSMR in MSC with very similar kinetics (Fig. S6A). RANKL, the key osteoclastogenic cytokine, was induced only 2 folds and only transiently by the LPS-activated $\mathrm{CD} 14^{+} \mathrm{CM}$ at day 1 of treatment, whereas its decoy receptor Osteoprotegerin (OPG) was reduced at the same time in all the cultures containing the osteoblast differentiation medium (Fig. 4A, arrows). Longer culture times indicated a reduced RANKL/OPG ratio with the LPS-activated $\mathrm{CD} 14^{+} \mathrm{CM}$, independently of gp130.

As shown in Fig. 5C, LPS-activated $\mathrm{CD} 14^{+} \mathrm{CM}$ or OSM induced the activation of STAT3 in MSC. Knock down of OSMR or STAT3 using siRNA (Fig. 5A and B) prevented induction of ALP mRNA by LPS-activated CD14 ${ }^{+} \mathrm{CM}$, whereas the role of LIFR was weaker (Fig. 5D). Similarly, OSMR and STAT3 but not LIFR were implicated in ALP induction by OSM (Fig. S6B). 
Adenoviral gene transfer of OSM induces bone formation in mice. Overexpression of OSM in the joint or injection of recombinant OSM in the calvaria can lead to induced bone resorption, bone formation or both, depending on the experimental context $(12,27,28)$. We developed a new approach based on injection of adenoviruses encoding murine OSM (AdOSM) in the tibia of C57BL/6 mice. After 7 days, X-ray micro-CT scan analysis and histology indicated that a bone healing reaction was initiated in the control animals injected with PBS or AdGFP (Fig. 6A and D). OSM overexpression significantly induced woven bone formation locally at the injury site with increased metaphyseal trabecular bone volume (BV/TV, Fig. 6B), trabecular thickness (Fig. 6C), collagen deposition (Fig. 6D) and osteoblast number (Fig. 6G and H). In contrast, osteoclasts were grossly absent in the bone healing zone and the metaphyseal osteoclast surface in the AdOSM groups was reduced, although not significantly (p=0.08, Fig. $6 \mathrm{E}$ and $\mathrm{F})$.

\section{Discussion}

In this study we report that activated monocytes/macrophages secrete coupling factors to induce mineralization by MSC. Whereas osteoclasts induce osteoblast differentiation through the Wnt and BMP pathways (2), activated monocytes/macrophages appear to do so mainly through OSM. We have identified this inflammatory cytokine using high throughput quantitative RT-PCR and multiplexed assays and validated its implication in the coupling between macrophages and osteoblasts using a panel of neutralizing antibodies and siRNA. Some Wnt and BMP members are induced by LPS in monocytes but their neutralization using a similar approach as the one described for osteoclasts (Dkk1 and BMP6 antibodies)(2) does 
not prevent mineralization induced by LPS-activated monocytes/macrophages. We consider it likely that macrophages are also implicated in MSC migration and chemoattraction to the inflammatory site, but it remains to determine the role of OSM, Wnt, BMP and chemokines in this initial step of osteogenesis.

OSM is a known product of activated macrophages where its expression is regulated by a PGE2-cAMP-PKA pathway $(17,26)$ in contrast to IL-6 which is directly induced through the TLR-NFkB pathway (29) and IL-6R protein which is known to be reduced by LPS (30). We propose here that insufficient sIL-6R production render IL-6 unable to stimulate osteoblast differentiation in our culture model, whereas OSM is produced in sufficient amount, in a COX2-PGE2 dependent manner. Interestingly, nonsteroidal antiinflammatory drugs (NSAIDs) such as COX2 inhibitors have an inhibitory effect on fracture repair and spinal fusion $(31,32)$. Our results suggest that NSAIDs could inhibit osteogenesis in part through reduction of OSM production by macrophages. Moreover, OSM production and hence regulation of matrix mineralization appeared largely restricted to classically activated inflammatory M1 macrophages, with various exogenous (from bacteria, viruses or fungi) or endogenous (from breakdown of the extracellular matrices) TLR ligands being similarly active. These results suggest that bone formation could be induced by macrophagesderived OSM in numerous conditions of inflammation, infection or injury and is not associated with M2 macrophages, despite their known role in tissue repair $(4,5)$. These observations are in line with recent studies showing that osteal macrophages implicated in bone formation or healing are inflammatory and produced high amount of TNF $\alpha$ upon TLR activation $(3,10)$.

Addition of sIL-6R to MSC cultures allows activated monocytes to stimulate mineralization and high concentrations of sIL-6R are normally found in the circulation (30, 
33). Therefore IL-6 could be also implicated in bone formation in vivo pending that its soluble receptor is provided by other cell sources such as liver cells. The third cytokine with a significant role in bone formation appeared to be LIF, but its production is restricted to MSC. Indeed LPS can directly stimulate mineralization on MSC through enhanced LIF synthesis. This pathway of bone formation is rather weak when considered alone but it presumably acts additively or synergistically with OSM or IL-6, forming a complex network of autocrine / paracrine regulations between M1 macrophages and MSC / osteoblasts (Fig. 5E). Monocytes from few donors ( 2 on 8 tested) appear to produce lower amount of OSM, and in that case the production of LIF from MSC appears to compensate the insufficient secretion of OSM. These donors could have a particular inflammatory status, such as increased nonclassical CD16 ${ }^{+}$ monocytes or skewed differentiation into M2 macrophages, but a larger cohort is needed to ascertain this possibility.

Several inflammatory cytokines such as IL-1 $\beta$, TNF $\alpha$, IL-6 and OSM are inhibitors of adipocyte differentiation and play a role in atrophy of adipose tissue connected to cancer cachexia and chronic inflammatory diseases (34). We show here that osteoblast differentiation induced by activated monocytes occurs at the expense of adipocyte differentiation and that OSM dictates this lineage commitment. Indeed OSM inhibits C/EBP $\alpha$ and PPAR $\gamma$ expression, the two key transcription factors implicated in adipogenesis $(27,34)$. In contrast OSM induces expression of $\mathrm{C} / \mathrm{EBP} \delta$ in MSC, as observed previously in other cell types (35). This basic leucine zipper transcription factor is transcriptionally controlled by STAT3 and acts synergistically with Cbfa1 to induce genes that are important for osteoblast replication and differentiation such as Osteocalcin and IGF-I $(36,37)$. We demonstrate here that OSM induces osteoblast differentiation and matrix mineralization through STAT3, with induced 
expression of $\mathrm{C} / \mathrm{EBP} \delta, \mathrm{Cbfa} 1, \mathrm{ALP}$ and BSP. All these events are also induced by activated monocytes in a gp130-dependent manner and are schematically presented in Fig. 5E.

In human, OSM can bind to 2 types of receptors complexes, the gp130+OSMR and gp130+LIFR complexes, whereas in mice OSM has long been thought to signal only through the gp130+OSMR complex. However, this concept has recently been challenged and is still a matter of debate. Indeed, $\mathrm{OSMR}^{-/-}$mice have reduced bone formation and increased adipogenesis but recombinant OSM is still able to induce bone formation in $\mathrm{OSMR}^{-/-}$mice apparently through the gp130+LIFR complex in osteocytes by downregulation of sclerostin, an inhibitor of bone formation (27). Using knock-down experiments, we show here that OSM or activated monocytes induce osteoblast differentiation in human MSC mainly through the gp130+OSMR complex, in a STAT3 dependent manner, leading to accelerated matrix mineralization. The smaller effect of LIFR knock-down presumably reflects the smaller role of LIF produced by MSC cells. We also provide evidence that overexpression of murine OSM in the tibia of mice leads to enhanced woven bone formation in the medullar cavity, expanding previous reports showing that murine OSM induces bone formation in the calvaria (27). Together, these results indicate that activated monocytes/macrophages produce OSM to form new bone, by stimulating MSC differentiation through the OSMR-STAT3-C/EBP $\delta$ Cbfa1 pathway (Fig. 5E). We cannot however exclude the possibility that activated monocytes / macrophages also induce bone formation in vivo through the gp130+LIFR complex in osteocytes.

In addition to bone formation, OSM is known to stimulate bone resorption by osteoclasts indirectly through induction of the RANKL/OPG ratio in bone stromal cells (19, 27). We show here that induction of RANKL expression in MSC by activated monocytes is small and very transient and the RANKL/OPG ratio is rather reduced in long term cultures. In 
addition, overexpression of OSM in the tibia of mice does not show any sign of induced osteoclast formation or bone resorption. Therefore, in the experimental contexts presented here, OSM appears as a much more active cytokine for bone formation than for bone degradation, in line with the known role of osteal macrophages in anabolic bone modeling independently of bone resorption (10). One previous study described that macrophages produce OSM to induce ALP expression and mineralization by vascular smooth muscle cells, suggesting a key role for this cytokine in vascular calcification associated with atherosclerosis (11). OSM is also well known to be produced by macrophages and neutrophils locally in the synovium of RA patients where it participates to joint destruction (17, 18). However, overexpression of OSM in the joint of mice also leads to periosteal bone formation, suggesting that OSM could have a role in bone apposition observed at varying degree and anatomic sites in RA, juvenile arthritis and spondyloarthropathies such as psoriatic arthritis and ankylosing spondylitis $(28,38)$. Similarly, IL-6 was shown to stimulate fracture healing and bone mechanical resistance (39). LIFR ${ }^{-/}$mice are osteopenic with induced osteoclast formation and reduced bone formation (40), and null mutations in LIFR leads to the StüveWiedemann syndrome in humans characterized by skeletal defects (41). Therefore the IL-6 family cytokine and signaling network activated by macrophages and TLR ligands could stimulate bone formation largely uncoupled from bone resorption and thus appears as an important target for anabolic bone therapies.

\section{Materials and Methods}

Cell isolation. Ethical approval for the use of bone marrow and peripheral blood from healthy donors was obtained from the Nantes University Hospital Ethics Committee. Samples were obtained from the orthopedic department and the "Etablissement Français du Sang" with informed consent. 
For MSC, 10-20 $\mathrm{ml}$ of bone marrow was harvested by iliac crest aspiration from 6 donors (age $=46 \pm 12$; range $=36-67)$. MSCs were obtained as previously described (42) and cultured in proliferation medium composed of Dulbecco's Modified Eagle Medium (DMEM; Lonza, Basel, Switzerland), 10\% foetal bovine serum (FBS; Hyclone Perbio, Bezons, France), 1 $\mathrm{ng} / \mathrm{ml}$ basic fibroblast growth factor (bFGF; R\&D systems, Minneapolis, MN, USA), 100 $\mathrm{U} / \mathrm{ml}$ penicillin, $100 \mathrm{U} / \mathrm{ml}$ streptomycin and $2 \mathrm{mM}$ L-glutamine. Adherent cells were frozen at passage two after characterization by flow cytometry $\left(\mathrm{CD} 45^{-}, \mathrm{CD} 34^{-}, \mathrm{CD} 105^{+}, \mathrm{CD}^{+} 3^{+}\right.$and $\mathrm{CD} 90^{+}$, purity $\geq 99 \%$ ) prior to further experiments. In addition, these cells were able to differentiate into osteoblast, adipocyte or chondrocyte (see below).

For $\mathrm{CD} 14^{+}$monocytes, peripheral blood mononuclear cells (PBMCs) from 8 different donors (age $=58 \pm 8$; range $=45-67$ ) were isolated by centrifugation over Ficoll gradient (Sigma Chemicals Co., St. Louis, MO). $\mathrm{CD}^{+} 4^{+}$cells were magnetically labelled with CD14 microbeads and positively selected by MACS technology (Miltenyi Biotec, Bergisch Gladbach, Germany). For CD11b ${ }^{+}$monocytes, the bone marrow of one donor (age=55) was harvested, mononuclear cells were isolated and sorted using CD11b microbeads. CD14 ${ }^{+}$and $\mathrm{CD}_{11 \mathrm{~b}^{+}}$cells were $\mathrm{CD}^{-}$by flow cytometry (purity $\geq 95 \% ; 5-10 \%$ of the $\mathrm{CD} 14^{+}$cells were $\mathrm{CD}_{16}{ }^{+}$nonclassical monocytes) and were frozen prior to further experiments.

Osteoblast differentiation. Before passage 5, MSC were seeded at $10^{4}$ cells $/ \mathrm{cm}^{2}$ in 96 wells plates in proliferation medium and allowed to attach and reach confluence. After 3 days, the medium was changed without bFGF but supplemented with vitamin D3 $\left(10^{-8} \mathrm{M}\right.$; HoffmannLa Roche, Basel, Switzerland) and dexamethasone $\left(10^{-7} \mathrm{M}\right.$; Sigma), with or without treatments as indicated (this represented day 0 for MSC osteogenic differentiation). Three days later, freshly prepared ascorbic acid (50 $\mu \mathrm{g} / \mathrm{ml}$; Sigma) and $\beta$-glycerophosphate (10 mM; Sigma) was added to allow mineralization, this medium being changed every 2-3 days. 
Alizarin red-S staining was used to detect the mineralized nodules formed in vitro as described previously (43). Briefly, between day 12 to 15 , cells were fixed in ice-cold $70 \%$ ethanol for $1 \mathrm{~h}$ and incubated with alizarin red-S (40 mM, pH 7.4; Sigma) for 10 minutes at room temperature. After extensive washing, images were captured using a stereo microscope (Stemi 2000-C; Zeiss, Oberkochen, Germany), and mineralized surfaces were quantify using the Qwin software (Leica, Nussloch, Germany).

Adipocyte differentiation. 20,000 MSC were seeded in Lab-Tek Chamber Slides (Nunc) in proliferation medium. After 3 days, when the confluence was reached, cells were cultured in adipogenic medium without bFGF but containing 3-Isobutyl-1-methylxanthine (IBMX 0.5 $\mathrm{mM}$; Sigma), indomethacin (60 $\mu \mathrm{M}$; Sigma) and dexamethasone ( $1 \mu \mathrm{M}$; Sigma) with medium replenishment every 2-3 days. After 19 days, cells were fixed with paraformaldehyde 4\% for $10 \mathrm{~min}$ and intracellular lipid droplets and nuclei were stained using respectively Nile red (Sigma) and dapi (Invitrogen, Cergy Pontoise, France). Cells with lipid droplets were counted manually using a fluorescent DMRXA microscope (Leica).

Monocyte / macrophage conditioned media. Activated $\mathrm{CD} 14^{+}$and $\mathrm{CD} 11 \mathrm{~b}^{+}$monocyte / macrophage CM were generated from $2.5 \times 10^{6}$ freshly resuscitated cells cultured for 3 days in $2 \mathrm{ml}$ of $\alpha$-MEM (Lonza) supplemented with $10 \%$ FBS and antibiotics, and treated with LPS, poly I:C, Zymosan A, hyaluronic acid from human umbilical cord, heparan sulfate from bovine kidney and/or meloxicam (all from Sigma at indicated concentrations). For M1 and M2 macrophages, CD14 ${ }^{+}$monocytes were cultured with GM-CSF $(20 \mathrm{ng} / \mathrm{ml})$ together with IFN $\gamma(50 \mathrm{ng} / \mathrm{ml}$; M1) or IL-4 (50 ng/ml; M2a) or IL-10 (50 ng/ml; M2c) for 2 days and then treated with LPS (100 ng/ml) for 3 additional days. Cells and debris were removed by centrifugation ( $5 \mathrm{~min}, 1600 \mathrm{rpm})$, and supernatants were aliquoted and stored at $-20^{\circ} \mathrm{C}$. 
Real-time PCR and RNA interference. Total RNA was extracted from MSC cultures using NucleoSpin RNA II (Macherey-Nagel, Hoerd, France). First-strand cDNA was synthesized from $1 \mu \mathrm{g}$ total RNA, using ThermoScript RT-PCR System (Invitrogen). The real-time PCR contained $10 \mathrm{ng}$ reverse-transcribed total RNA, $300 \mathrm{nM}$ primers and SYBR green buffer (Biorad, Marnes-la-Coquette, France)(44). Quantitative PCRs (qPCRs) were carried out on a CFX96 Real-Time PCR Detection System (Biorad). Analysis was performed using human $\beta 2$ microglobuline $(\beta 2 \mathrm{~m})$, cytochrome $\mathrm{c}-1$ (cyc1) and hypoxanthine guanine phosphoribosyl transferase (HPRT) as invariant controls. For the high throughput quantitative RT-PCR on monocytes / macrophages, see the Table S1 legend. For RNA interference, MSC were transfected with Interferin (PolyPlus-transfection, Illkirch, France) and annealed siRNA (10 nM; Ambion, Applied Biosystems, Courtabouef, France) according to the manufacturer's recommendations. The siRNA references were LIFR (s8170), OSMR (s17542) and STAT3 (s743).

Cytokines, neutralizing antibodies, ELISA and multiplexed assays. We measured IL- $1 \alpha$, IL-1 $\beta$, IL-1RA, IL-7, IL-15, IL-6, LIF, IL-12p70, IL-23, IL-10, CCL2, CCL3, CCL4, CCL5, CCL7, CCL24, CXCL8, CXCL9, CXCL10, CXCL11, IFN $\beta$, IFN $\gamma$, Lta, VEGFA, G-CSF, GM-CSF and FGF2 levels in conditioned media using the multiplexed Luminex technology (Bio-Plex Pro Assays from Biorad and Milliplex MAP kits from Millipore, Molsheim, France). Additionally, PGE2, OSM, IL6, sIL6R, TRAIL and M-SCF release in conditioned media were quantified using ELISA assays (R\&D Systems) according to the manufacturers' instructions. Unless otherwise stated, all cytokines and neutralizing antibodies used here are from R\&D Systems (see also Table S1 legend). 
Western Blot. Cells were lysed in RIPA buffer and analyzed as described (44). The membranes were blotted with antibodies to P-STAT3 (Tyr705), STAT3 (Cell Signaling Technologies, Beverly, MA, USA) or actin (Sigma).

In Vivo experiments. All researches involving animals were conducted following the guidelines of and have been approved by the French ethical committee CEEA.PdL.06 and by local veterinary services (licence $\mathrm{n}^{\circ} \mathrm{C} 44015$ ). Researches involving viruses have been approved by the French Ministry of Research "commission de Génie Génétique" (licence $\mathrm{n}^{\circ}$ 5698). Replication-deficient adenovirus encoding mouse OSM (AdOSM) has been described previously $(44,45)$ and was produced, together with adenovirus encoding green fluorescent protein (AdGFP), in the vector facility of the INSERM U649 Laboratory (Nantes, France). 8 weeks old male C57BL/6 mice (Janvier, Le Genest-Saint-Isle, France) were treated with intra-tibial injection with either AdOSM or AdGFP at a dose of $5.10^{7} \mathrm{pfu}$. After sacrifice by $\mathrm{CO} 2$ inhalation, tibias were fixed in $10 \%$ buffered formaldehyde during 1 week. Bone architecture was analyzed using the high-resolution SkyScan-1076 X-ray microcomputed tomography system for small animal imaging (SkyScan, Kartuizersweg, Belgium). The relative trabecular bone volume (BV/TV) and other trabecular variables (number and thickness) were quantified in the metaphyseal spongiosa using the SkyScan CtAn software.

Histology. Injected tibias were decalcified with $4.13 \%$ EDTA and $0.2 \%$ paraformaldehyde in PBS during 96 hours using the KOS microwave histostation (Milestone, Kalamazoo, MI) before embedding in paraffin. Five $\mu$ m-thick sections were analyzed by Masson trichrome and TRAP (tartrate-resistant acid phosphatase) staining as described previously (44, 45). Immunostaining for osterix was performed as described (44) with a rabbit anti-osterix antibody (1/25; Abcam, Cambridge, MA, USA). Quantification of relative osteoclast surface 
$\left(\mathrm{TRAP}^{+}\right.$cells) and osteoblast number (osterix ${ }^{+}$cells) in the metaphyseal spongiosa was evaluated by Qwin (Leica) and ImageJ (NIH, Bethesda, MD, USA) softwares. All analyses were assessed by light microscopy using a DMRXA microscope (Leica).

Statistical analysis. Results were analysed with unpaired t-test or 1-way ANOVA followed by Fisher's post-hoc test using GraphPad InStat v3.02 software. Results are given as mean \pm $\mathrm{SD}$ (for in vitro experimentations) or mean $\pm \mathrm{SEM}$ (for in vivo experimentations) and results with $\mathrm{p}<0.05$ were considered significant.

Acknowledgments. We thank the Vector Core of the University Hospital of Nantes (France) supported by the Association Française contre les Myopathies (AFM) for producing the adenovirus vectors. We are very grateful to Maria Cristina Cuturi, Claire Usal, Emmanuel Merieau and Ignacio Anegon (Inserm U643, Nantes, France) for animal care and their help in the experimental design. This work was supported by Inserm, le Ministère de la Recherche, and La Ligue Contre le Cancer (comité Grand Ouest). P.G. is a recipient from a fellowship from le Ministère de la Recherche.

\section{References}

1. Theoleyre S, et al. (2004) The molecular triad OPG/RANK/RANKL: involvement in the orchestration of pathophysiological bone remodeling. Cytokine Growth Factor Rev 15(6):457-475.

2. Pederson L, Ruan M, Westendorf JJ, Khosla S, \& Oursler MJ (2008) Regulation of bone formation by osteoclasts involves Wnt/BMP signaling and the chemokine sphingosine-1-phosphate. Proc Natl Acad Sci U S A 105(52):20764-20769.

3. Chang MK, et al. (2008) Osteal tissue macrophages are intercalated throughout human and mouse bone lining tissues and regulate osteoblast function in vitro and in vivo. $J$ Immunol 181(2):1232-1244.

4. Benoit M, Desnues B, \& Mege JL (2008) Macrophage polarization in bacterial infections. J Immunol 181(6):3733-3739. 
5. Hamilton JA \& Tak PP (2009) The dynamics of macrophage lineage populations in inflammatory and autoimmune diseases. Arthritis Rheum 60(5):1210-1221.

6. Kwan Tat S, Padrines M, Theoleyre S, Heymann D, \& Fortun Y (2004) IL-6, RANKL, TNF-alpha/IL-1: interrelations in bone resorption pathophysiology. Cytokine Growth Factor Rev 15(1):49-60.

7. Jimenez-Boj E, et al. (2005) Interaction between synovial inflammatory tissue and bone marrow in rheumatoid arthritis. J Immunol 175(4):2579-2588.

8. Walsh NC \& Gravallese EM (2010) Bone remodeling in rheumatic disease: a question of balance. Immunol Rev 233(1):301-312.

9. Glass GE, et al. (2011) TNF-alpha promotes fracture repair by augmenting the recruitment and differentiation of muscle-derived stromal cells. Proc Natl Acad Sci U $S$ A 108(4):1585-1590.

10. Alexander KA, et al. (2011) Osteal macrophages promote in vivo intramembranous bone healing in a mouse tibial injury model. J Bone Miner Res 26(7):1517-1532.

11. Shioi A, et al. (2002) Induction of bone-type alkaline phosphatase in human vascular smooth muscle cells: roles of tumor necrosis factor-alpha and oncostatin $\mathrm{M}$ derived from macrophages. Circ Res 91(1):9-16.

12. Blanchard F, Duplomb L, Baud'huin M, \& Brounais B (2009) The dual role of IL-6type cytokines on bone remodeling and bone tumors. Cytokine Growth Factor Rev 20(1):19-28.

13. Wong PK, Campbell IK, Egan PJ, Ernst M, \& Wicks IP (2003) The role of the interleukin- 6 family of cytokines in inflammatory arthritis and bone turnover. Arthritis Rheum 48(5):1177-1189.

14. Franchimont N, Wertz S, \& Malaise M (2005) Interleukin-6: An osteotropic factor influencing bone formation? Bone 37(5):601-606.

15. Atreya R \& Neurath MF (2005) Involvement of IL-6 in the pathogenesis of inflammatory bowel disease and colon cancer. Clin Rev Allergy Immunol 28(3):187196.

16. Alenius GM, Eriksson C, \& Rantapaa Dahlqvist S (2009) Interleukin-6 and soluble interleukin-2 receptor alpha-markers of inflammation in patients with psoriatic arthritis? Clin Exp Rheumatol 27(1):120-123.

17. Cawston TE, et al. (1998) The role of oncostatin M in animal and human connective tissue collagen turnover and its localization within the rheumatoid joint. Arthritis Rheum 41(10):1760-1771.

18. Cross A, Edwards SW, Bucknall RC, \& Moots RJ (2004) Secretion of oncostatin M by neutrophils in rheumatoid arthritis. Arthritis Rheum 50(5):1430-1436.

19. Palmqvist P, Persson E, Conaway HH, \& Lerner UH (2002) IL-6, leukemia inhibitory factor, and oncostatin $\mathrm{M}$ stimulate bone resorption and regulate the expression of receptor activator of NF-kappa B ligand, osteoprotegerin, and receptor activator of NF-kappa B in mouse calvariae. J Immunol 169(6):3353-3362.

20. Fonseca JE, Santos MJ, Canhao H, \& Choy E (2009) Interleukin-6 as a key player in systemic inflammation and joint destruction. Autoimmun Rev.

21. Itoh S, et al. (2006) A critical role for interleukin-6 family-mediated Stat3 activation in osteoblast differentiation and bone formation. Bone 39(3):505-512.

22. Song HY, Jeon ES, Kim JI, Jung JS, \& Kim JH (2007) Oncostatin M promotes osteogenesis and suppresses adipogenic differentiation of human adipose tissuederived mesenchymal stem cells. J Cell Biochem 101(5):1238-1251.

23. Bellido T, Borba VZ, Roberson P, \& Manolagas SC (1997) Activation of the Janus kinase/STAT (signal transducer and activator of transcription) signal transduction 
pathway by interleukin-6-type cytokines promotes osteoblast differentiation. Endocrinology 138(9):3666-3676.

24. Pene J, et al. (2008) Chronically inflamed human tissues are infiltrated by highly differentiated Th17 lymphocytes. J Immunol 180(11):7423-7430.

25. Chevalier S, et al. (1996) Interleukin-6 family of cytokines induced activation of different functional sites expressed by gp130 transducing protein. $J$ Biol Chem 271(25):14764-14772.

26. Repovic P \& Benveniste EN (2002) Prostaglandin E2 is a novel inducer of oncostatinM expression in macrophages and microglia. J Neurosci 22(13):5334-5343.

27. Walker EC, et al. (2010) Oncostatin M promotes bone formation independently of resorption when signaling through leukemia inhibitory factor receptor in mice. $J$ Clin Invest 120(2):582-592.

28. de Hooge AS, et al. (2002) Adenoviral transfer of murine oncostatin M elicits periosteal bone apposition in knee joints of mice, despite synovial inflammation and up-regulated expression of interleukin-6 and receptor activator of nuclear factor-kappa B ligand. Am J Pathol 160(5):1733-1743.

29. Dendorfer U, Oettgen P, \& Libermann TA (1994) Multiple regulatory elements in the interleukin-6 gene mediate induction by prostaglandins, cyclic AMP, and lipopolysaccharide. Mol Cell Biol 14(7):4443-4454.

30. Dekkers PE, et al. (2000) Endotoxin down-regulates monocyte and granulocyte interleukin-6 receptors without influencing gp130 expression in humans. J Infect Dis 181(3):1055-1061.

31. Altman RD, et al. (1995) Effect of nonsteroidal antiinflammatory drugs on fracture healing: a laboratory study in rats. J Orthop Trauma 9(5):392-400.

32. Glassman SD, et al. (1998) The effect of postoperative nonsteroidal anti-inflammatory drug administration on spinal fusion. Spine (Phila Pa 1976) 23(7):834-838.

33. Desgeorges A, et al. (1997) Concentrations and origins of soluble interleukin 6 receptor-alpha in serum and synovial fluid. $J$ Rheumatol 24(8):1510-1516.

34. Miyaoka Y, Tanaka M, Naiki T, \& Miyajima A (2006) Oncostatin M inhibits adipogenesis through the RAS/ERK and STAT5 signaling pathways. $J$ Biol Chem 281(49):37913-37920.

35. Hutt JA \& DeWille JW (2002) Oncostatin M induces growth arrest of mammary epithelium via a CCAAT/enhancer-binding protein delta-dependent pathway. Mol Cancer Ther 1(8):601-610.

36. Shin CS, et al. (2006) CCAAT/enhancer-binding protein delta activates the Runx2mediated transcription of mouse osteocalcin II promoter. J Mol Endocrinol 36(3):531546.

37. McCarthy TL, et al. (2000) Runt domain factor (Runx)-dependent effects on CCAAT/ enhancer-binding protein delta expression and activity in osteoblasts. $J$ Biol Chem 275(28):21746-21753.

38. de Hooge AS, et al. (2003) Growth plate damage, a feature of juvenile idiopathic arthritis, can be induced by adenoviral gene transfer of oncostatin M: a comparative study in gene-deficient mice. Arthritis Rheum 48(6):1750-1761.

39. Rozen N, et al. (2007) Fracture repair: modulation of fracture-callus and mechanical properties by sequential application of IL-6 following PTH 1-34 or PTH 28-48. Bone 41(3):437-445.

40. Ware CB, et al. (1995) Targeted disruption of the low-affinity leukemia inhibitory factor receptor gene causes placental, skeletal, neural and metabolic defects and results in perinatal death. Development 121(5):1283-1299. 
41. Dagoneau N, et al. (2004) Null leukemia inhibitory factor receptor (LIFR) mutations in Stuve-Wiedemann/Schwartz-Jampel type 2 syndrome. Am J Hum Genet 74(2):298305.

42. Tarte K, et al. (2010) Clinical-grade production of human mesenchymal stromal cells: occurrence of aneuploidy without transformation. Blood 115(8):1549-1553.

43. Chipoy C, et al. (2004) Downregulation of osteoblast markers and induction of the glial fibrillary acidic protein by oncostatin $\mathrm{M}$ in osteosarcoma cells require PKCdelta and STAT3. J Bone Miner Res 19(11):1850-1861.

44. David E, et al. (2011) Direct anti-cancer effect of oncostatin M on chondrosarcoma. Int J Cancer 128(8):1822-1835.

45. Brounais B, et al. (2008) Oncostatin M induces bone loss and sensitizes rat osteosarcoma to the antitumor effect of Midostaurin in vivo. Clin Cancer Res 14(17):5400-5409.

\section{Figure Legends}

Fig. 1. Activated monocytes/macrophages induced mineralization by MSC. (A) Human bone marrow MSC (20 000 cells) were co-cultured with human circulating CD14 $4^{+}$monocytes (200 000 cells) in the osteoblast differentiation medium (Diff) and treated with LPS (100 $\mathrm{ng} / \mathrm{ml}$ ) or RANKL (100 ng/ml) for 15 days as indicated. (B) MSC were treated with the CM (diluted 1/10) of LPS-activated CD14 ${ }^{+}$monocytes from 4 different donors. All cultures were fixed after 15 days, stained with Alizarin red S, quantified and expressed relative to the control culture with differentiation medium only. (C) MSC were cultured in the adipocyte differentiation medium (Diff) and treated with the CM (1/10) of LPS-activated CD14 monocytes as indicated. Cultures were fixed after 15days, stained with Nile red (lipid droplets) and dapi (nuclei) and photographed (original magnification, X100). All assays were performed with $\mathrm{n}=3$ to 5 for each condition and are representative of at least 2 independent experiments. Results are expressed as the mean $+/-\mathrm{SD} .{ }^{*} \mathrm{p}<0.05$ compared to the indicated culture or to the control with differentiation medium only if not indicated. CT CM, control $\mathrm{CM}$ from $\mathrm{CD} 14^{+}$monocytes without LPS. 
Fig. 2. OSM is a major mediator secreted by LPS-activated monocytes and implicated in the mineralization by MSC. (A) CD14 $4^{+}$monocytes obtained from 3 different donors were treated or not with LPS (100 $\mathrm{ng} / \mathrm{ml})$ for $8 \mathrm{~h}$ and mRNA expression was assessed by real-time PCR. On the 161 tested genes, the expression of 56 genes was significantly modulated by LPS above control $(\mathrm{CT})$ in the $3 \mathrm{CD}^{+} 4^{+}$cultures. Results are presented as normalized expression $\left(\mathrm{x} 10^{-3}\right)$ using the indicated color code. A list of 15 candidate coupling factors with known activities on osteoblast differentiation was then established from the literature (in red). See Table S1 legend for more details. (B) MSC were treated with indicated cytokines (100 ng/ml) in the osteoblast differentiation medium. ${ }^{*} \mathrm{p}<0.05$ compared to the culture without cytokine. (C) MSC were treated in the osteoblast differentiation medium with increasing concentrations of OSM, LIF, sIL-6R in presence of $100 \mathrm{ng} / \mathrm{ml}$ of IL-6, or IL-6 in presence of $100 \mathrm{ng} / \mathrm{ml}$ of sIL-6R. (D) MSC were treated in the osteoblast differentiation medium with 4 different LPSactivated $\mathrm{CD}^{+} \mathrm{CM}$ (LPS, 1/10) and neutralizing antibodies $(10 \mu \mathrm{g} / \mathrm{ml})$ as indicated. ${ }^{*} \mathrm{p}<0.05$ compared to the culture treated with the control mouse antibody (IgG). Mineralization was quantified and expressed as in Fig. 1 except in D where it is expressed relative to the control antibody. (E) MSC were cultured in the adipocyte differentiation medium (Diff) and treated with OSM $(10 \mathrm{ng} / \mathrm{ml})$ or the CM $(1 / 10)$ of LPS-activated CD14 ${ }^{+}$ monocytes as indicated for 15 days. Cultures were stained as in Fig. 1C and adipocytes containing lipid droplets were counted in 3 different fields ( $>300$ total cells). ${ }^{*} p<0.05$ compared to the control with differentiation medium only. All assays were performed with $\mathrm{n}=3$ to 5 for each condition and are representative of at least 2 independent experiments. Results are expressed as the mean $+/-\mathrm{SD}$. CT, control $\mathrm{CM}$ from $\mathrm{CD} 14^{+}$monocytes without LPS. 
Fig. 3. OSM is produced in M1 macrophages upon various TLRs activations through a COX2/PGE2 regulatory loop. (A) CD14 $4^{+}$monocytes were treated with LPS $(100 \mathrm{ng} / \mathrm{ml})$ and Meloxicam (Melo, $100 \mu \mathrm{M}$, a COX2 inhibitor) as indicated. Their CM (1/10) was then used to treat MSC. Mineralization was quantified and expressed as in Fig. 1. (B) Levels of PGE2, OSM, IL-6 and sIL-6R in indicated CD14+ CM were determined by ELISA. (C) CD14 ${ }^{+}$ monocytes were cultured with GM-CSF together with IFN $\gamma$ (M1) or IL-4 (M2a) or IL-10 (M2c) for 2 days and then treated with LPS (100 ng/ml) for 3 additional days. (D) CD14 monocytes were treated with LPS $(100 \mathrm{ng} / \mathrm{ml})$, poly I:C $(25 \mu \mathrm{g} / \mathrm{ml})$, Zymosan $(5 \mu \mathrm{g} / \mathrm{ml})$, hyaluronic acid (HA, $10 \mu \mathrm{g} / \mathrm{ml}$ ) or heparan sulfate (HS, $100 \mu \mathrm{g} / \mathrm{ml}$ ) for 3 days. OSM secretion was determined by ELISA. (E, F, G, H) Indicated monocytes / macrophages CM (1/10) were used to treat MSC in presence or absence of OSM or gp130 neutralizing antibodies (10 $\mu \mathrm{g} / \mathrm{ml}$ ). Original images are shown in E and G. Mineralization was quantified and expressed as in Fig. 1 in F and H. All assays were performed with $n=3$ to 5 for each condition and are representative of at least 2 independent experiments. Results are expressed as the mean $+/$ SD. ${ }^{*} \mathrm{p}<0.05$.

Fig. 4. Regulated genes in MSC. MSC were treated as indicated in the differentiation medium (refer to Fig. 1 and 2 legends). (A) mRNA expression of indicated genes was assessed by realtime PCR. Assays were performed with $n=2$ for each condition and are representative of 2 independent experiments. Arrows indicate the only time point where the RANKL/OPG ratio is induced by the LPS-activated $\mathrm{CD} 14^{+} \mathrm{CM}$. (B) Cultures were analyzed for mineralization after 8, 12, 15 and 18 days as in Fig. 1. Results are expressed relative to the control culture with differentiation medium only at day 15. LPS, LPS-activated CD14 CM (1/10); gp130, 
neutralizing anti-gp130 antibody $(10 \mu \mathrm{g} / \mathrm{ml}) ; \beta$-gly, $\beta$-glycerophosphate; asc. ac, ascorbic acid.

Fig. 5. Role of OSMR, LIFR and STAT3. MSC were transfected with control siRNA (siCT) or siRNA for OSMR, LIFR or STAT3. (A) mRNA expression of OSMR or LIFR were reduced by more than $70 \%$ as assessed 2 days after transfection by real time PCR. (B) STAT3 expression was also reduced using specific siRNA as assessed by western blot. (C) MSC were treated with OSM $(10 \mathrm{ng} / \mathrm{ml})$, LPS $(10 \mathrm{ng} / \mathrm{ml})$, control or LPS-activated CD14 ${ }^{+} \mathrm{CM}(1 / 10)$ for 15 min. Phosphorylation of STAT3 was analyzed by western blot. (D) 2 days after siRNA transfection, MSC were treated with LPS-activated CD14 ${ }^{+} \mathrm{CM}$ in the differentiation medium. After $24 \mathrm{~h}$ of treatment, MSC were analyzed for ALP mRNA expression by real time PCR. Assays were performed with $\mathrm{n}=2$ for each condition and are representative of 2 independent experiments. ${ }^{*} p<0.05$ compared to the control siRNA. (E) Schematic representation of the coupling between activated monocyte-macrophage and MSC-osteoblast based on the present study. See the text for a detailed description.

Fig. 6. OSM induces bone formation in mice. Indicated adenoviruses $\left(5 \times 10^{7} \mathrm{pfu}\right)$ were injected in the tibia of C57BL/6 mice. After 7 days, animals were sacrificed and tibias were analyzed by X-ray micro-CT scan. Representative sagital sections are shown in A, the relative trabecular bone volume (BV/TV) and thickness $(\mathrm{Tb} . \mathrm{Th})$ in $\mathrm{B}$ and $\mathrm{C}(\mathrm{n}=6$ in each group, representative of 2 independent experiments). The same tibias were fixed, included, sectioned and stained as described in Experimental procedures with Masson's trichrome (D, collagen fibers stained in green) or for TRAP (E, osteoclasts stained in red) and osterix (G, osteoblasts 
stained in red). Positive cells in the metaphyseal spongiosa were quantified using the Qwin and ImageJ softwares. Results are expressed as relative TRAP ${ }^{+}$osteoclast surface (Oc.S, F) or osterix $^{+}$osteoblast number $(\mathrm{Ob} . \mathrm{N}, \mathrm{H})$ with $\mathrm{n}=6-7$ per group. Columns, mean; bars, SEM; ${ }^{*} \mathrm{p}<0.05$ between AdOSM and AdGFP group; arrows, passage of the syringe; $\neq$, new woven bone induced by the AdOSM; BM, bone marrow; v, blood vessel. Original magnification: X50 (D and E); X200 (G). 

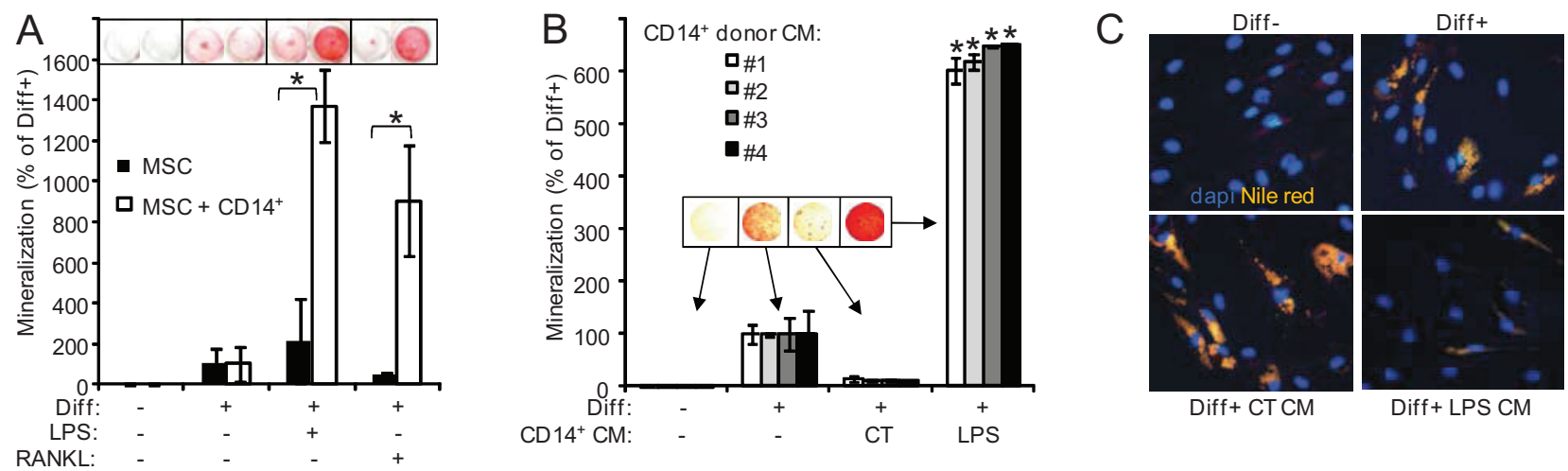

RANKL: - $\quad-\quad-\quad$ - 

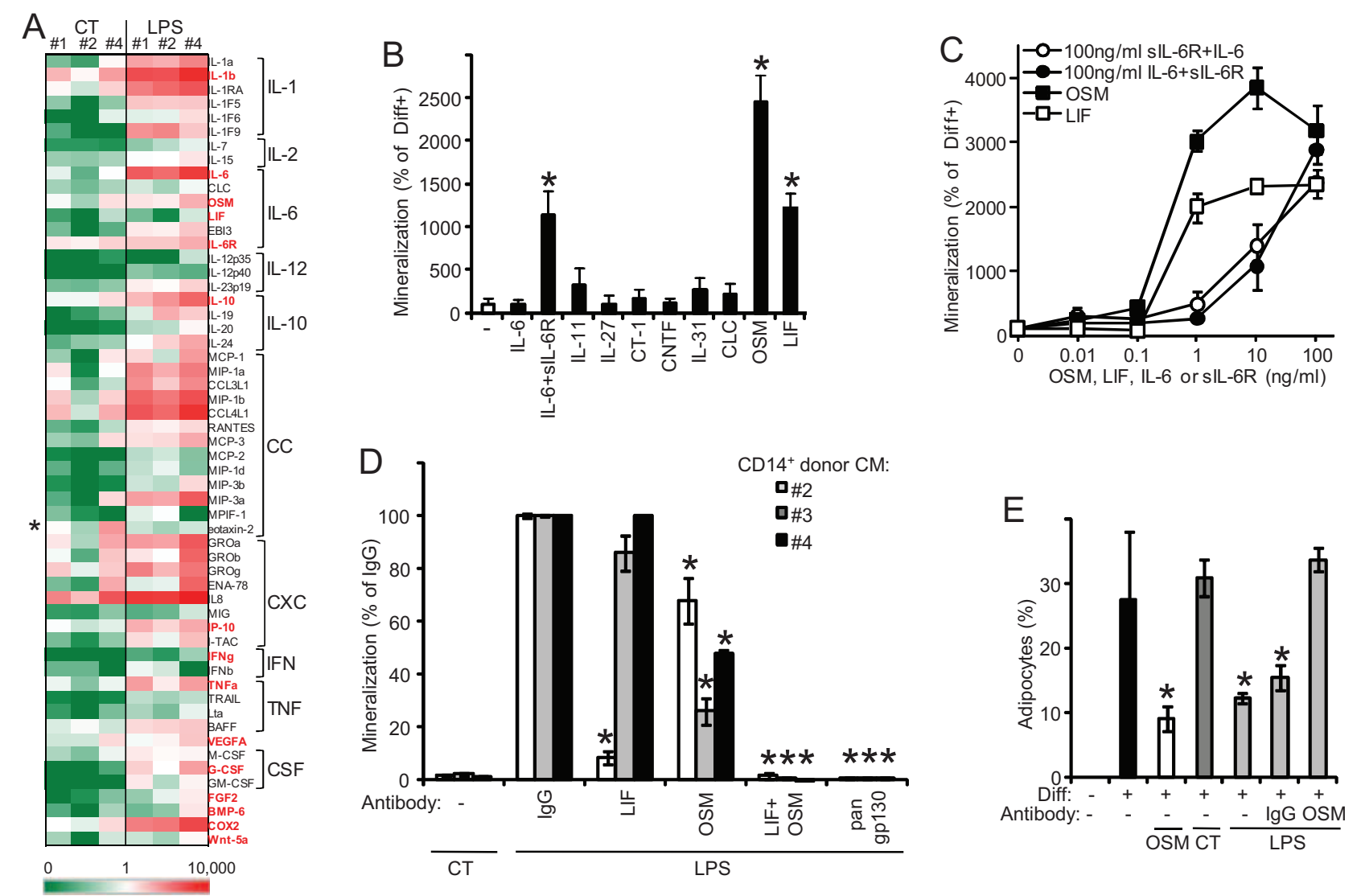

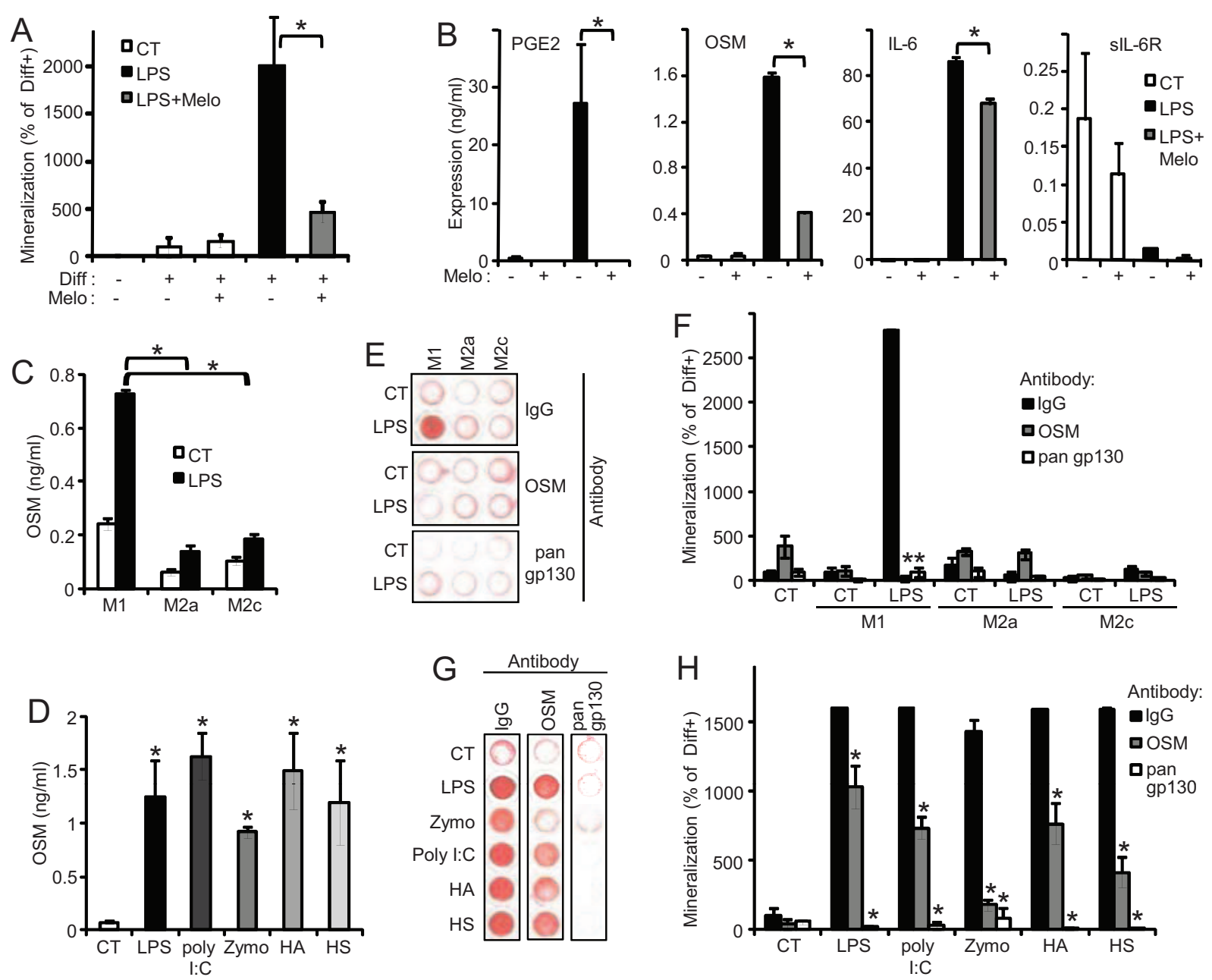


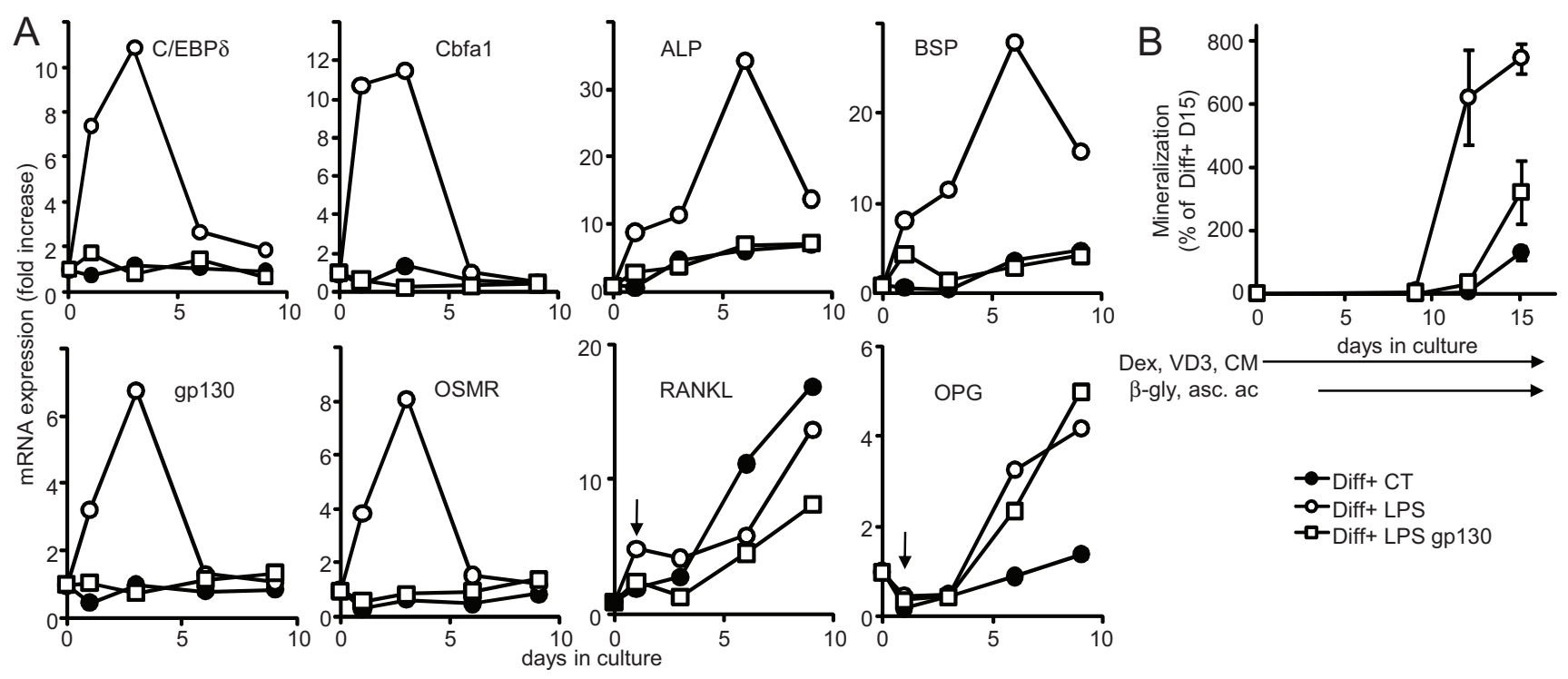




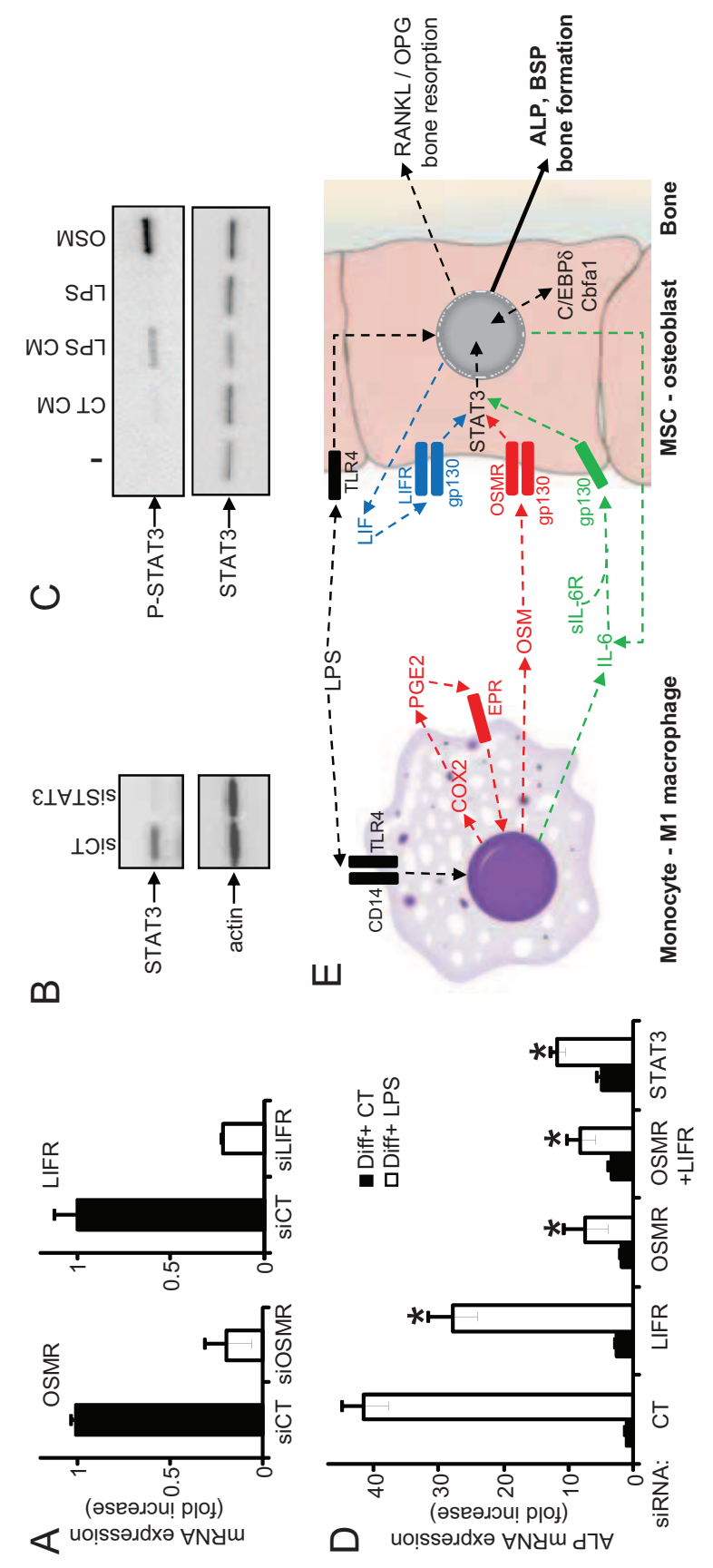



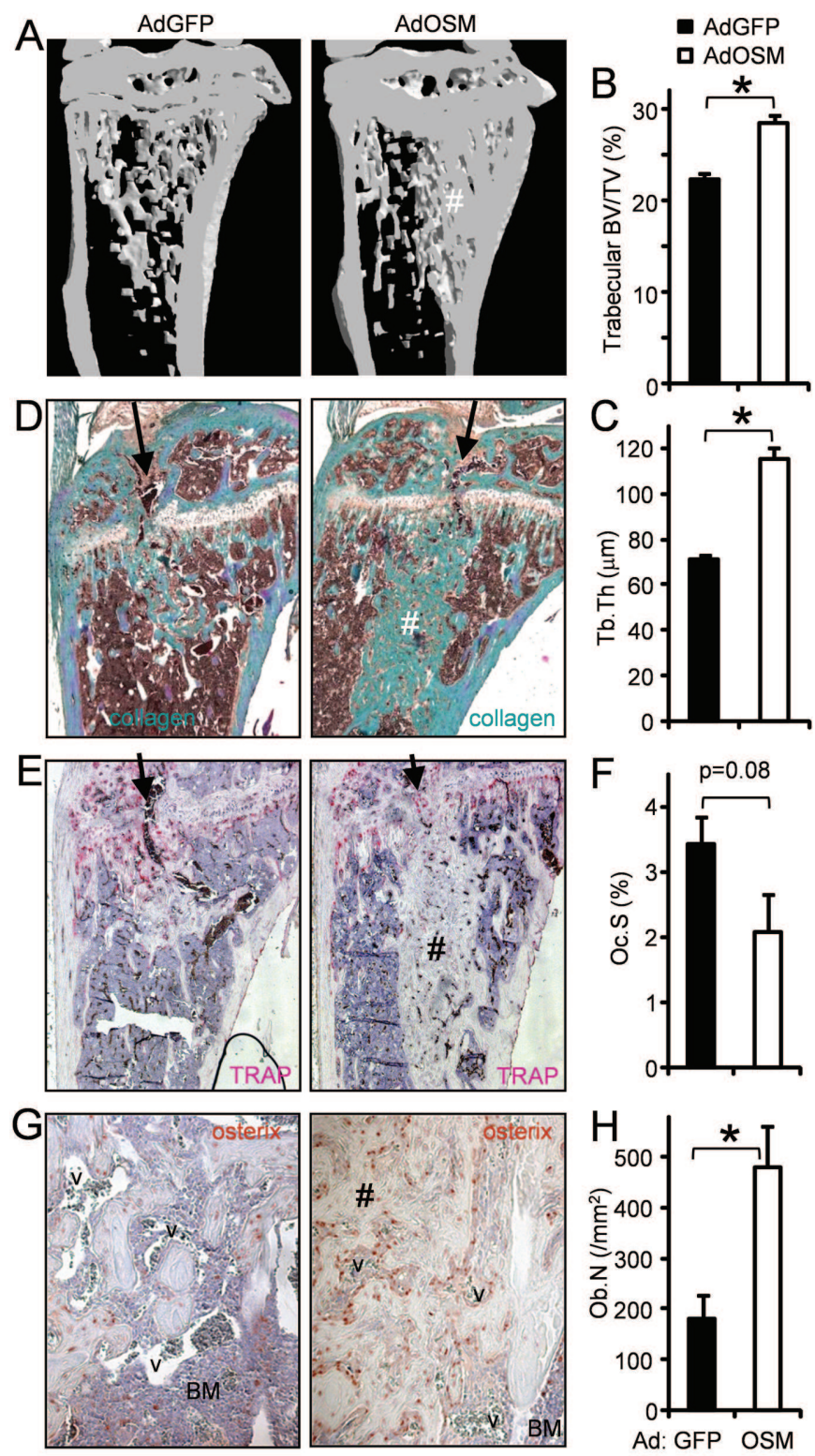

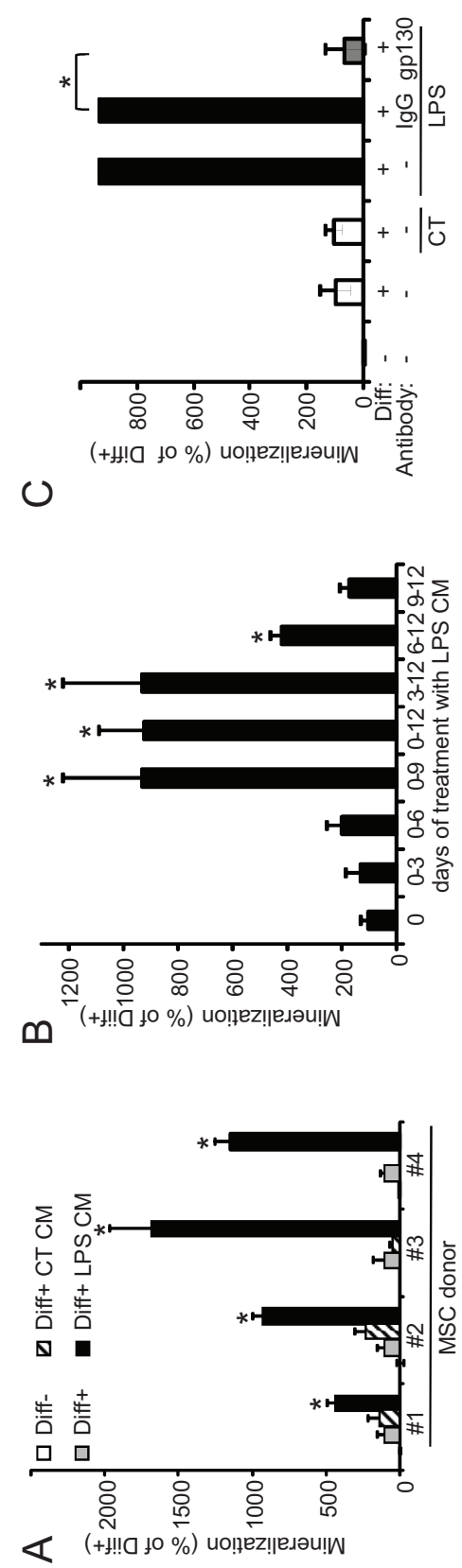

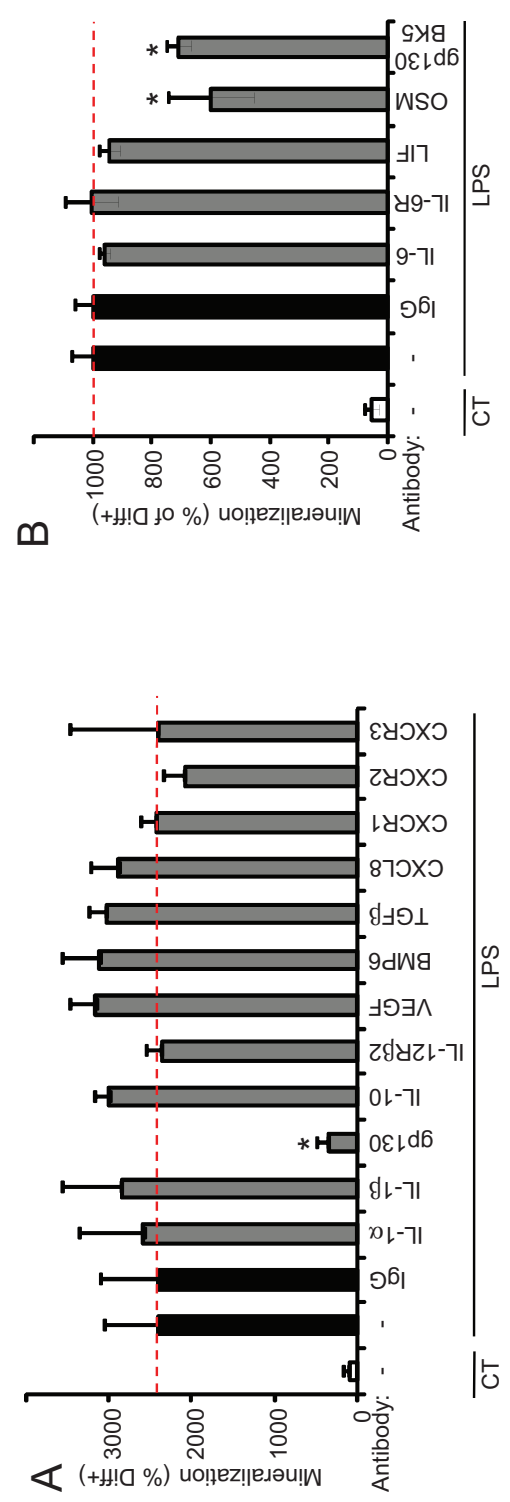

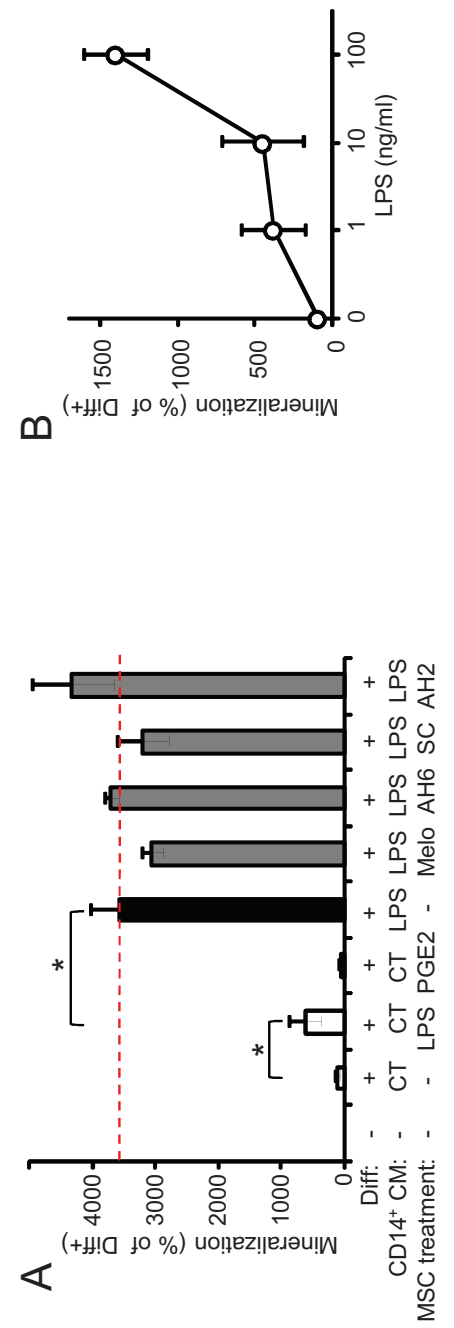

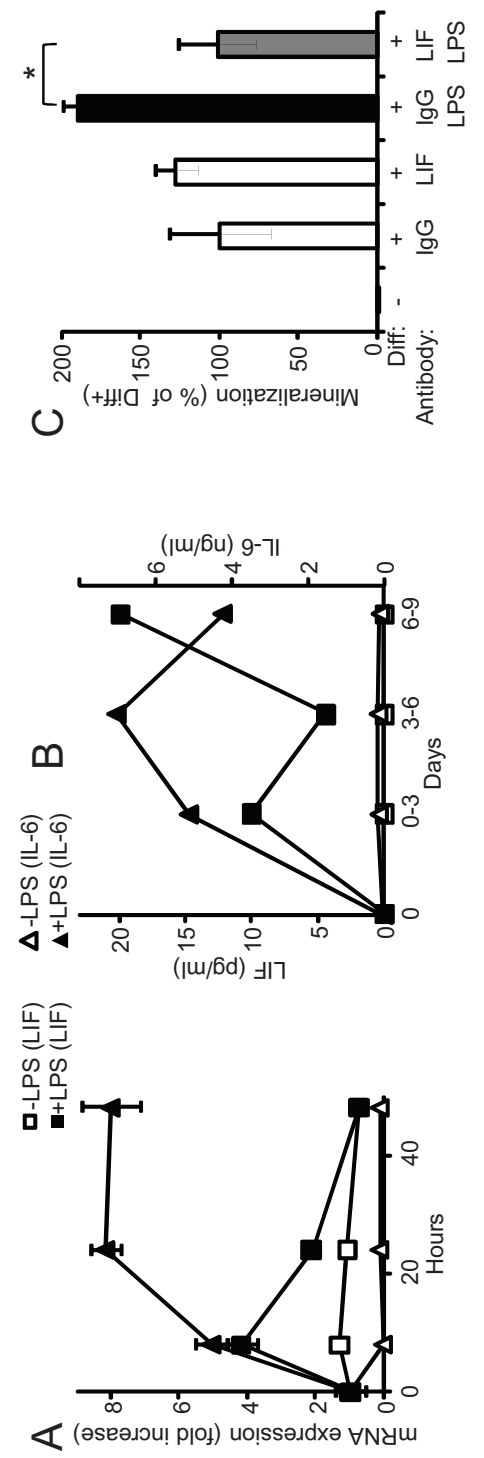


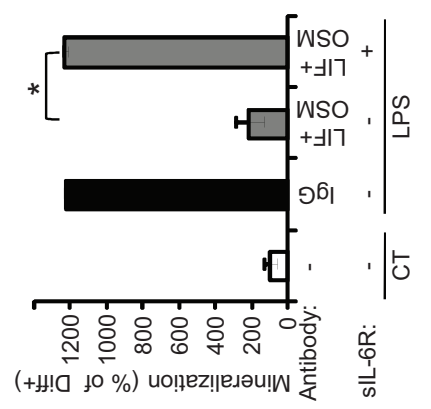



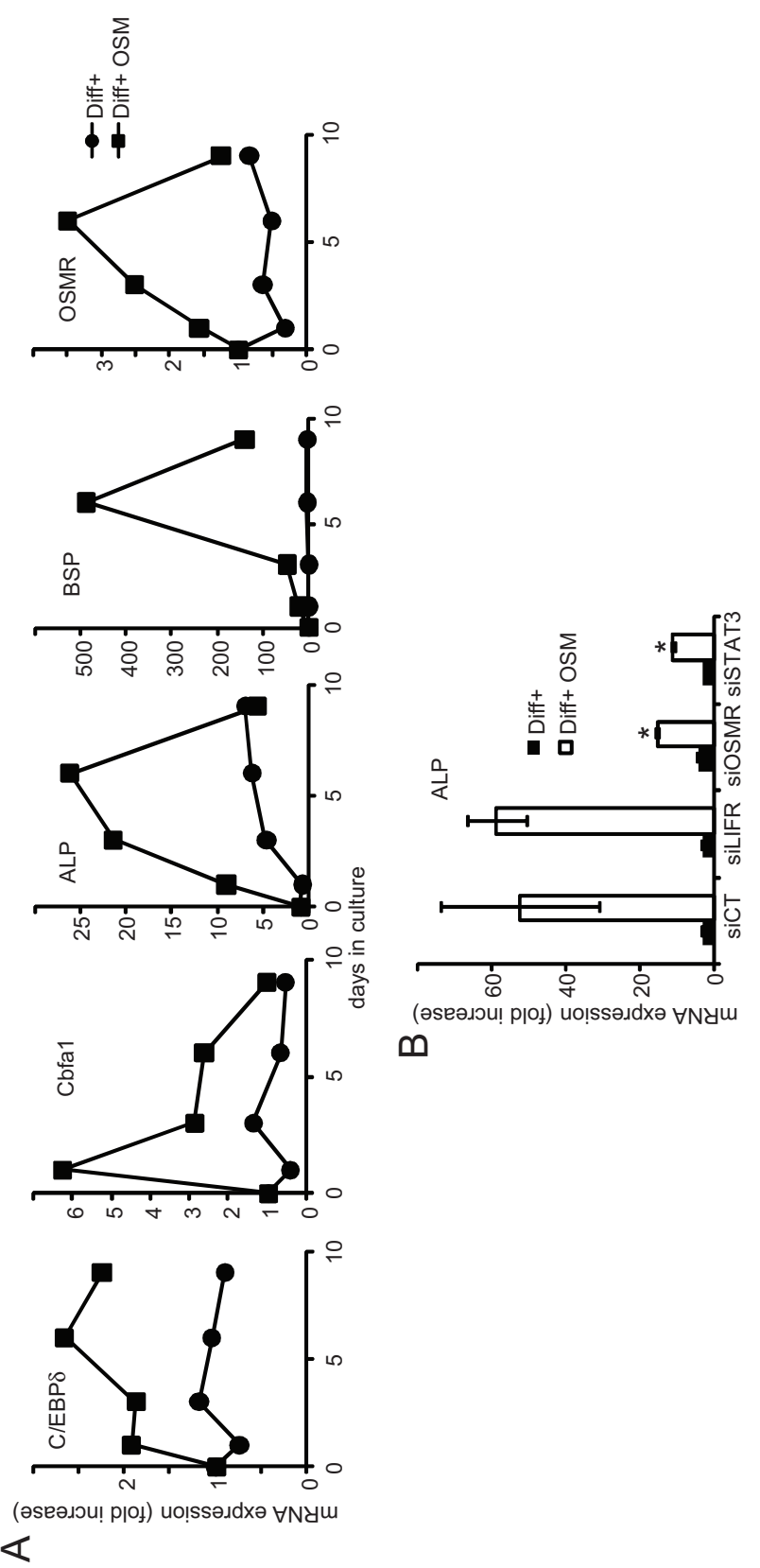


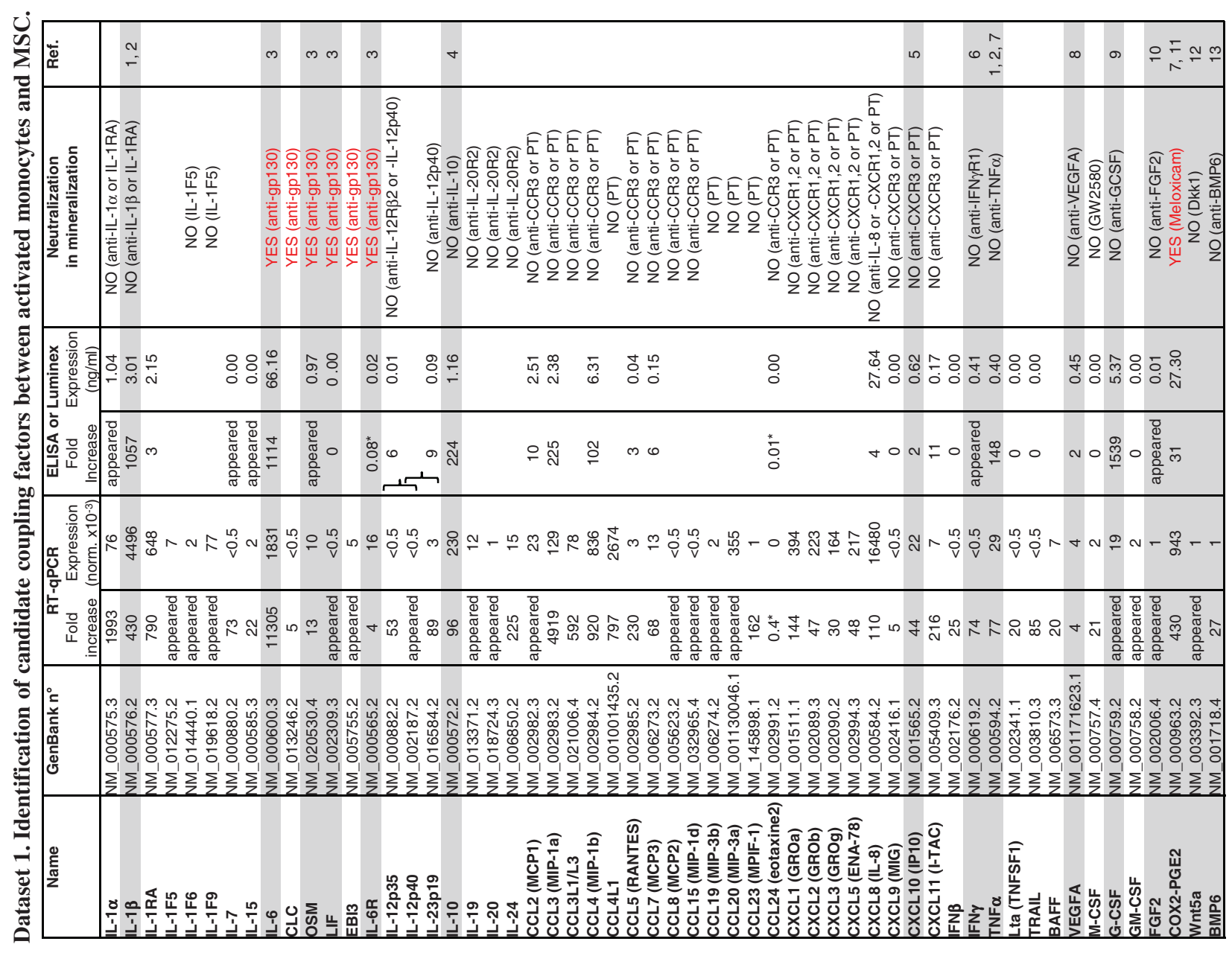




\section{SI Figures and datasets legends.}

Fig. S1. (A) MSC from 4 different donors were treated in the osteoblast differentiation medium with a CM (1/10) of CD14 ${ }^{+}$monocytes treated with LPS as indicated. (B) MSC were treated in the osteoblast differentiation medium with a LPS-activated CD14 ${ }^{+} \mathrm{CM}(1 / 10)$ during the indicated time frame. (C) MSC were treated in the osteoblast differentiation medium with a LPS-activated bone marrow $\mathrm{CD} 11 \mathrm{~b}^{+}$monocytes $\mathrm{CM}(1 / 10$, LPS) and gp130 neutralizing antibodies $(10 \mu \mathrm{g} / \mathrm{ml})$. All cultures were fixed after 12 days, stained with Alizarin red $\mathrm{S}$, quantified and expressed relative to the control culture with differentiation medium only. Assays were performed with $\mathrm{n}=5$ for each condition and are representative of 2 independent experiments. Results are expressed as the mean $+/-\mathrm{SD} .{ }^{*} p<0.05$ compared to the control with differentiation medium only, unless otherwise indicated.

Fig. S2. (A, B) MSC were treated in the osteoblast differentiation medium with LPS-activated CD14 ${ }^{+}$monocytes CM (1/10, LPS), neutralizing antibodies $(10 \mu \mathrm{g} / \mathrm{ml})$ or Dkk1 $(1 \mu \mathrm{g} / \mathrm{ml})$ as indicated for 12 days. Dkk1 and all antibodies were from R\&D Systems, except IL-6R (clone BR6) and gp130 (clone BK5) antibodies from Diaclone (Besançon, France). Mineralization was quantified and expressed as in Fig. 1. Assays were performed with $n=4$ for each condition and are representative of 2 independent experiments. Results are expressed as the mean $+/-$ SD. ${ }^{*} \mathrm{p}<0.05$ compared to the control IgG.

Fig. S3. (A) Human MSC were treated in the osteoblast differentiation medium with LPS (10 $\mathrm{ng} / \mathrm{ml})$, PGE2 (3 ng/ml), LPS-activated CD14 ${ }^{+} \mathrm{CM}(1 / 10$, LPS), Meloxicam $(100 \mu \mathrm{M})$ and prostaglandin EP receptor inhibitors AH6809 (AH6, $10 \mu \mathrm{M})$, SC19220 (SC, $100 \mu \mathrm{M})$ or $\mathrm{AH} 23848(\mathrm{AH} 2,10 \mu \mathrm{M})($ all from Cayman Chemicals) as indicated for 12 days. (B) MSC were treated in the osteoblast differentiation medium with increasing concentrations of LPS for 15 days. Mineralization was quantified and expressed as in Fig. 1. Assays were performed with $\mathrm{n}=4$ for each condition and are representative of 2 independent experiments. Results are expressed as the mean $+/$ - SD. ${ }^{*} \mathrm{p}<0.05$.

Fig. S4. MSC were treated with LPS $(10 \mathrm{ng} / \mathrm{ml})$ in the osteoblast differentiation medium for indicated time. (A) MSC were analyzed by real-time PCR for LIF or IL-6 mRNA expression. (B) The conditioned media were analyzed for LIF and IL-6 secretion by ELISA. (C) MSC were similarly treated with LPS together with LIF neutralizing antibodies for 15 days. Mineralization was quantified and expressed as in Fig. 1. All assays were performed with $\mathrm{n}=3-4$ for each condition and are representative of 2 independent experiments. Results are expressed as the mean $+/$ - SD. ${ }^{*} \mathrm{p}<0.05$.

Fig. S5. MSC were treated in the osteoblast differentiation medium with LPS-activated CD14 $4^{+}$monocytes CM (1/10, LPS), neutralizing antibodies $(10 \mu \mathrm{g} / \mathrm{ml})$ and sIL-6R (100 $\mathrm{ng} / \mathrm{ml}$ ) as indicated for 12 days. Mineralization was quantified and expressed as in Fig. 1. Assays were performed with $n=4$ for each condition and are representative of 2 independent experiments. Results are expressed as the mean $+/-\mathrm{SD} .{ }^{*} \mathrm{p}<0.05$.

Fig. S6 (A) MSC were treated in the osteoblast differentiation medium with OSM (10 ng/ml). mRNA expression of indicated genes was assessed by real-time PCR. (B) MSC were transfected with indicated siRNA as in Fig. 5, treated with OSM $(10 \mathrm{ng} / \mathrm{ml})$ for $24 \mathrm{~h}$ in the osteoblast differentiation medium and analyzed for ALP mRNA expression by real-time PCR. Assays were performed with $\mathrm{n}=2$ for each condition and are representative of 2 independent experiments. ${ }^{*} \mathrm{p}<0.05$ compared to the control siRNA. 
Dataset 1. CD $14^{+}$monocytes obtained from 3 different donors were treated or not with LPS $(100 \mathrm{ng} / \mathrm{ml})$ for $8 \mathrm{~h}$. Total RNA was extracted, subjected to cDNA synthesis and PCR amplifications reactions were conducted as described (14). The $\Delta \mathrm{Ct}$ method was retained for quantification and GAPDH, HPRT1 and $H S P C B$ housekeeping genes used for multiple normalization as described previously (15). On the 161 tested genes, the expression of 56 genes was significantly modulated by LPS in the $3 \mathrm{CD}_{1} 4^{+}$cultures and is presented here. Results are presented as the mean fold increase over the culture without LPS and as the mean normalized expression after treatment with LPS. A list of 15 candidate coupling factors with known activities on osteoblast differentiation was then established from the literature (in grey with indicated references). The secretion of 33 soluble mediators was then analyzed in the conditioned medium of $\mathrm{CD}^{+} 4^{+}$monocytes ( 3 donnors) treated or not with LPS $(100 \mathrm{ng} / \mathrm{ml})$ for 3 days using the Luminex technology (Bio-Rad laboratories and Millipore) or ELISA (R\&D systems). Results are presented as the mean fold increase over the culture without LPS and as the mean expression after treatment with LPS. The activity of 46 soluble mediators was then neutralized in the mineralization assay using neutralizing antibodies $(10 \mu \mathrm{g} / \mathrm{ml}$, all from R\&D systems except anti-IL-12p40 from Dr Gascan, France, and anti-IL-20R2 from Genentech, USA, ref 16), GW2580 (15 $\mu \mathrm{M}$, a c-FMS inhibitor, EMD Chemicals), Pertussis Toxin (PT, $1 \mu \mathrm{g} / \mathrm{ml}$, Santa Cruz Biotechnology), IL-1RA, IL-1F5 or Dkk1 $(1 \mu \mathrm{g} / \mathrm{ml}, \mathrm{R} \& \mathrm{D}$ systems)(see the experimental procedures and Fig. 2 legend). The production of PGE2 by $\mathrm{CD}_{14}{ }^{+}$monocytes was inhibited using the COX2 inhibitor Meloxicam $(100 \mu \mathrm{M}) .^{*}$, reduced expression after LPS treatment.

1. Lacey DC, Simmons PJ, Graves SE, Hamilton JA. (2009) Proinflammatory cytokines inhibit osteogenic differentiation from stem cells: implications for bone repair during inflammation. Osteoarthritis Cartilage. 17(6):735-42.

2. Ding J, et al. (2009) TNF-alpha and IL-1beta inhibit RUNX2 and collagen expression but increase alkaline phosphatase activity and mineralization in human mesenchymal stem cells. Life Sci. 84(15-16):499-504.

3. Blanchard F, Duplomb L, Baud'huin M, Brounais B. (2009) The dual role of IL-6-type cytokines on bone remodeling and bone tumors. Cytokine Growth Factor Rev. 20(1):1928.

4. Dresner-Pollak R, Gelb N, Rachmilewitz D, Karmeli F, Weinreb M. (2004) Interleukin 10-deficient mice develop osteopenia, decreased bone formation, and mechanical fragility of long bones. Gastroenterology. 127(3):792-801.

5. Lisignoli G, et al. (2003) Human osteoblasts express functional CXC chemokine receptors 3 and 5: activation by their ligands, CXCL10 and CXCL13, significantly induces alkaline phosphatase and beta-N-acetylhexosaminidase release. $J$ Cell Physiol. 194(1):71-9.

6. Duque G, et al. (2009) Autocrine regulation of interferon gamma in mesenchymal stem cells plays a role in early osteoblastogenesis. Stem Cells. 27(3):550-8.

7. Lencel P, Delplace S, Hardouin P, Magne D. (2011) TNF- $\alpha$ stimulates alkaline phosphatase and mineralization through PPAR $\gamma$ inhibition in human osteoblasts. Bone. 48(2):242-9.

8. Maes C, et al. (2010) Increased skeletal VEGF enhances beta-catenin activity and results in excessively ossified bones. EMBO J. 29(2):424-41.

9. Christopher MJ, Link DC. (2008) Granulocyte colony-stimulating factor induces osteoblast apoptosis and inhibits osteoblast differentiation. $J$ Bone Miner Res. 23(11):1765-74.

10. Huang Z, Ren PG, Ma T, Smith RL, Goodman SB. (2010) Modulating osteogenesis of mesenchymal stem cells by modifying growth factor availability. Cytokine. 51(3):305-10. 
11. Zhang X, et al. (2002) Cyclooxygenase-2 regulates mesenchymal cell differentiation into the osteoblast lineage and is critically involved in bone repair. $J$ Clin Invest. 109(11):1405-15.

12. Takada I, et al. (2007) A histone lysine methyltransferase activated by non-canonical Wnt signalling suppresses PPAR-gamma transactivation. Nat Cell Biol. 9(11):1273-85.

13. Pederson L, Ruan M, Westendorf JJ, Khosla S, Oursler MJ. (2008) Regulation of bone formation by osteoclasts involves Wnt/BMP signaling and the chemokine sphingosine-1phosphate. Proc Natl Acad Sci U S A. 105(52):20764-9.

14. Pène J, et al. (2008) Chronically inflamed human tissues are infiltrated by highly differentiated Th17 lymphocytes. J Immunol. 180(11):7423-30.

15. Vandesompele J, et al. (2002) Accurate normalization of real-time quantitative RT-PCR data by geometric averaging of multiple internal control genes. Genome Biol 3:RESEARCH0034.

16. Sa SM, et al. (2007) The effects of IL-20 subfamily cytokines on reconstituted human epidermis suggest potential roles in cutaneous innate defense and pathogenic adaptive immunity in psoriasis. J Immunol. 178(4):2229-40. 